DOI: 10.12731/2658-6649-2019-11-2-65-123

УДК 616.12-008:616.89

\title{
ОРТОСТАТИЧЕСКАЯ ГИПОТЕНЗИЯ В ПСИХИАТРИИ (ОБЗОР ЛИТЕРАТУРЫ С КОММЕНТАРИЯМИ)
}

\author{
Беккер Р.А., Быков Ю.В.
}

Цель исследования. Представить читателю подробный обзор касательно эпидемиологии, факторов риска, этиологических причин и патогенетических механизмов развития ортостатической гипотензии в психиатрии. Показать, каким образом ортостатическая гипотензия 8 психиатрии может быть источником дополнительных психических проблем, или причиной развития резистентности к проводимому психотропному лечению. Представить несколько интересных клинических случаев ортостатической гипотензии в психиатрии, включая наш собственный.

Методология проведения работы. $\mathrm{Mbl}$ провели поиск в поисковых системах PubMed, Google Scholar, Science Direct, Web of Science c использованием ключевых слов «orthostatic hypotension» в сочетании с наименованиями различных психических патологий и психотропных препаратов. Найденные поиском статьи были проанализированы нами на предмет релевантности по отношению к тематике планируемой статьи. Затем мы представили результаты этого анализа в настоящем обзоре.

Результаты. В проиессе составления настоящего обзора нами найдены литературные данные, убедительно свидетельствующие о том, что ортостатическая гипотензия в психиатрии является не просто «ещё одним побочным эффектом», но нередким источником таких дополнительных психических проблем, как депрессия, тревога, патологическая сонливость, ухудшение когнитивного функиионирования паииентов, усиление экстрапирамидных побочных эффектов терапии. Кроме того, найденные нами литературные данные свидетельствуют также о том, что ортостатическая гипотензия в психиатрии может также быть одной из причин резистентности к проводимой терапии.

Нами также найдены литературные данные о факторах риска развития ортостатической гипотензии в психиатрии. Эти данные позволяют стратифицировать пациентов по группам риска, и заранее предпринять соответствующие меры по профилактике или минимизации риска возник- 
новения этого осложнения в уязвимых группах. Затем нами представлены клинические случаи, иллюстрирующуие выпеуказанные тезисы, в том числе один случай из нашей собственной практики.

Область применения результатов. Полученные нами результаты свидетельствуют о том, что проблему ортостатической гипотензии в психиатрии ни в коем случае нельзя игнорировать или недооценивать. Она заслуживает своевременного и проактивного выявления и энергичной коррекции. Это связано с тем, что ортостатическая гипотензия не только снижает качество жизни пациента и его комплаентность к лечению, но и служит источником дополнительных психических проблем, таких, как депрессия, тревога, когнитивные нарушения, чрезмерная сонливость. Она даже может быть причиной резистентности к психотропной терапии.

Ключевые слова: ортостатическая гипотензия; психофармакотерапия; электросудорожная терапия; когнитивные нарушения; депрессия; тревога; экстрапирамидная симптоматика; резистентность к лечению.

\title{
ORTHOSTATIC HYPOTENSION IN PSYCHIATRY (A LITERATURE REVIEW WITH AUTHORS' COMMENTS)
}

\author{
Bekker R.A., Bykov Yu.V.
}

Purpose. To provide the reader with a thorough overview of epidemiology, potential risk factors, etiological causes, and pathogenetic mechanisms of the development of orthostatic hypotension in psychiatry. To show how an orthostatic hypotension in psychiatry can be a source of additional mental problems, or a cause of the development of resistance to ongoing psychotropic treatment. To present some interesting clinical cases of orthostatic hypotension in psychiatry, including one case from our own practice.

Methodology. To complete this review, we have searched via different search engines, such as PubMed, Google Scholar, Science Direct, Web of Science, the combination of the keywords "orthostatic hypotension» with the names of various mental disorders and psychotropic drugs. The articles found by the search were then analyzed for relevance with respect to the topics of this article. The results of this analysis are compiled and presented in this review.

Results. The literature data that we have found convincingly indicate that orthostatic hypotension in psychiatry is not just "another side effect". It can be a source of several additional mental problems, such as depression, anxiety, 
pathological drowsiness, impaired cognitive functioning. Orthostatic hypotension can also seriously increase the frequency and severity of extrapyramidal side effects of psychotropic drugs. In addition, the literature data that we have found also suggests that orthostatic hypotension in psychiatry can also be one of the causes of treatment resistance.

We have also found literature data concerning risk factors for the development of orthostatic hypotension in psychiatry. This makes possible to stratify patients by risk groups, and to take appropriate measures in advance to prevent or minimize the risk of this complication in vulnerable groups. Next, we presented several clinical cases illustrating the above points, including one case from our own practice.

Practical implications. Our results indicate that the problem of orthostatic hypotension in psychiatry should never be ignored, underestimated or taken too lightly. This problem deserves timely and proactive identification and vigorous correction. This is due to the fact that orthostatic hypotension not only diminishes the patient's quality of life and can ruin the patient's compliance with treatment. It also serves as a frequent source of additional mental problems, such as depression, anxiety, cognitive problems, excessive sleepiness. Orthostatic hypotension can even be one of the often-overlooked causes of treatment resistance.

Keywords: orthostatic hypotension; psychopharmacotherapy; electroconvulsive therapy; cognitive decline; depression; anxiety; extrapyramidal symptoms; treatment resistance.

\section{ВВЕДЕНИЕ}

\section{(Определение и общие исторические сведения)}

Согласно общепринятому определению, ортостатической гипотензией (ОГ) называется снижение систолического артериального давления (САД) более чем на 20 мм.рт.ст. или диастолического артериального давления (ДАД) более чем на 10 мм.рт.ст. при резком переходе из лежачего положения в сидячее или стоячее, или из сидячего в стоячее, которое может сопровождаться или не сопровождаться какими-либо симптомами и жалобами [1].

В рамках настоящей статьи мы не будем рассматривать многообразные возможные общесоматические, неврологические и эндокринные причины развития ОГ, такие, как синдром Шая-Дреджера, рассеянный склероз (РС), идиопатическая ОГ, хроническая недостаточность коры или мозгового слоя надпочечников, хроническая венозная недостаточность (варикоз вен нижних конечностей, геморроидальная болезнь), недостаточность щито- 
видной железы (гипотиреоз) или, напротив, гипертиреоз, идиопатическая автономная нейропатия, хроническая сердечная недостаточность $(\mathrm{XCH})$, ишемическая болезнь сердца (ИБС), гипертоническая болезнь (ГБ), последствия острого инфаркта миокарда (ОИМ), различные анемии (в том числе вызванные дефицитом железа, фолатов или витамина $\mathrm{B}_{12}$ ), нейросифилис с поражением спинного мозга («спинная сухотка»), автономная нейропатия при болезни Паркинсона (БП), деменции телец Леви (ДТЛ), болезни Альцгеймера (БА), мультисистемной атрофии (МСА), сахарном диабете (СД), острая и хроническая гиповолемия, кровопотеря, рвота, понос, гипонатриемия, гипокалиемия, гипокальциемия или гипомагнеземия, приём гипотензивных лекарств, паранеопластический синдром при злокачественных новообразованиях и т. д.

Мы не будем также останавливаться на проблеме поиска возможных причин развития ОГ среди этих заболеваний, так как это выходит за рамки данной статьи. Эта статья посвящена исключительно рассмотрению ОГ как типичного побочного эффекта (ПЭ) психиатрических методов лечения.

Проблема ОГ, как типичного ПЭ психиатрических методов лечения, известна давно, практически с самого начала попыток биологического лечения пациентов с психическими заболеваниями. Так, в частности, ещё в эпоху широкого применения для седации этих пациентов препаратов опия (ещё до изобретения хлоралгидрата и барбитуратов), было известно, что большие дозы опия могут, наряду с сонливостью и угнетением дыхания, вызывать также ОГ [2].

Позднее ОГ, наряду с пролежнями и пневмонией, была одним из частых осложнений и одной из причин смертности пациентов при применении методики лечения длительным бромистым, хлоралгидратным или барбитуровым сном. Также ОГ часто встречалась и при применении таких биологических методов лечения, как пиротерапия («лихорадочная терапия»), инсулинокоматозная терапия (ИКТ), атропинокоматозная терапия (АКТ), электросудорожная терапия (ЭСТ), лечебный наркоз (ЛН) [2].

Но особую актуальность проблема ОГ приобрела именно после появления психофармакотерапии (ПФТ). Способность первых антипсихотиков (АП) - хлорпромазина и резерпина - вызывать тяжёлую ОГ, была известна с самого начала их клинического применения. Исторически первым человеком, упавшим в ортостатический обморок после применения хлорпромазина именно в психиатрическом контексте, была психиатр Корнелия Кварти, отважившаяся испытать действие хлорпромазина на себе, перед тем, как применить его на пациентах. Это осложнение было расценено как 
настолько серьёзное, что даже привело к тому, что руководство её клиники категорически запретило ей какие-либо дальнейшие эксперименты с хлорпромазином [2].

Аналогичным образом, с самого начала клинического применения первых антидепрессантов (АД) - ингибиторов моноаминоксидазы (ИМАО) и трициклических антидепрессантов (ТЦА) - было известно об их способности вызывать ОГ, нередко тяжёлую [2].

Длительное время ОГ в психиатрии воспринималась лишь как нежелательное, тяжёлое, а иногда даже смертельно опасное, осложнение лечения. Но лишь сравнительно недавно внимание специалистов привлёк другой аспект проблемы ОГ в психиатрии, а именно, её долгосрочный вред для психического состояния пациентов, в частности, её способность ухудшать течение психических заболеваний, вызывать когнитивные нарушения (КН), ухудшать память, концентрацию внимания у пациентов, усугублять депрессивную, тревожную, апато-абулическую симптоматику, сонливость, вялость, адинамию, усиливать проявления экстрапирамидного синдрома (ЭПС) и даже способствовать развитию резистентности к лечению [3]. Именно этот аспект и является предметом рассмотрения в настоящей статье.

\section{Проблема игнорирования или недоценки опасности}

\section{ортостатической гипотензии в психиатрии и её исторические корни}

На ранних этапах становления психофармакологии, ОГ и вызываемые ею снижение двигательной активности пациента, слабость, сонливость, апатия, наряду с ЭПС, нередко рассматривались не просто как неизбежные в то время ПЭ от применения ПФТ (они были неизбежны из-за доступности в те времена лишь типичных антипсихотиков - ТАП, а также ТЦА и ИМАО, и из-за отсутствия в те времена более специфичных, более селективных и лучше переносимых психотропных препаратов), но даже как желательная и необходимая часть лечебного эффекта ПФТ, которая якобы способствует более быстрому купированию психомоторного возбуждения, то есть - как своего рода «химическая смирительная рубашка» [2].

До того, как стал известен механизм антипсихотического действия хлорпромазина, и стало понятно, что он связан преимущественно с блокадой дофаминовых $\mathrm{D}_{2}$ рецепторов мезолимбической системы, некоторые из теорий, пытавшиеся объяснить его лечебное действие, связывали его действие с его $\alpha_{1}$-адреноблокирующей (и, соответственно, гипотензивной) активностью и/или с его антигистаминными, гипотермическими и седативными свойствами [2]. 
На ранних этапах становления психофармакологии это даже привело к целенаправленному синтезу левомепромазина (тизерцина), как соединения, обладающего и более выраженным $\alpha_{1}$-адреноблокирующим и гипотензивным, и более выраженным антигистаминным, седативным и гипотермическим действием [2].

Вызываемая АП постуральная гипотензия, наряду с гипотермией, сонливостью и седацией, а также наряду с ЭПС, в те времена рассматривались как важная и необходимая часть их действия и как одно из проявлений общего угнетения ЦНС. Известна, в частности, история о том, что вначале хлорпромазин применяли в комбинации с обкладыванием пациентов льдом, потому что полагали гипотермическое действие критически необходимым для достижения лечебного эффекта [2].

Отголоски этого отношения к ОГ на фоне приёма АП или АД, как к чему-то достаточно безобидному, а порой даже необходимому и полезному для более быстрого купирования психомоторного возбуждения, встречаются до сих пор. Однако, как указывают Л. Перлмуттер с соавторами, такое отношение нельзя назвать иначе, чем безответственным и легкомысленным. С позиций наших сегодняшних знаний ОГ на фоне лечения АП или АД - явление безусловно нежелательное и вредное. Это явление, которого следует всеми силами стремиться избежать, не в меньшей мере, чем мы ныне стремимся избежать появления ЭПС или акатизии, чрезмерной сонливости или седации, прибавки массы тела и метаболических нарушений [3].

\section{Определение ортостатических синдромов}

Согласно общепринятому определению, ОГ называется снижение САД более чем на 20 мм.рт.ст. или ДАД более чем на 10 мм.рт.ст. от исходного при резком переходе из лежачего положения в сидячее или стоячее, или из сидячего в стоячее, могущее сопровождаться или не сопровождаться какими-либо симптомами и жалобами [1]. Если оно не сопровождается какими-либо симптомами или жалобами, то такая ОГ называется бессимптомной.

Другой важный ортостатический синдром - это ортостатическая тахикардия (OT). Она определяется как чрезмерное (более чем на 30 уд/мин, у детей и подростков - более чем на 40 уд/мин) увеличение частоты сердечных сокращений (ЧСС) при резком переходе из лежачего положения в сидячее или стоячее, или из сидячего в стоячее, без снижения артериального давления или при незначительном его изменении в любую сторону (менее чем на 20 мм.рт.ст. для САД или 10 мм.рт.ст. для ДАД), могущая сопровождаться или не сопровождаться какими-либо иными симптомами кроме тахикардии [1]. 
Стоит отметить, что ОТ рассматривается как субклиническая ОГ состояние, при котором значительное повышение ЧСС компенсирует снижение артериального давления. Однако при наличии других неблагоприятных факторов, таких, например, как воздействие высокой температуры внешней среды, повышение температуры тела, обильный приём пищи, физическая нагрузка или сексуальная активность, состояние может декомпенсироваться и ОГ может проявиться клинически [1].

Третий важный ортостатический синдром представляет собой явление, внешне противоположное ОГ - ортостатическую гипертензию (ОГт). Согласно общепринятому определению, ОГт называется повышение САД более чем на 20 мм.рт.ст. от исходного при резком переходе из лежачего положения в сидячее или стоячее, или из сидячего в стоячее, либо повышение ДАД до абсолютных цифр, превышающих 98 мм.рт.ст., при тех же условиях. Важно отметить, что ОГ и ОГт - это не взаимоисключающие состояния, и что вовсе не исключено одновременное наличие у одного и того же пациента в одних ситуациях (при одних измерениях) ОГ, а при других - ОГт [1].

Более того, наличие ОГт предрасполагает к развитию в последующем эпизодов ОГ и наоборот. Причиной этого является дизрегуляция нормальной функции барорефлекторной дуги, участвующей в поддержании нормального артериального давления при изменении положения тела. Вследствие этого в одних случаях избыточная барорефлекторная регуляция приводит к чрезмерному повышению артериального давления в стоячем положении, а в других случаях - недостаточность барорефлекторной регуляции приводит к развитию ОГ [1].

Четвёртый важный ортостатический синдром называется ортостатической интолерантностью (ОИ). Она определяется как появление тех или иных неприятных симптомов (например, ортостатических головокружений, ортостатической головной боли, ортостатических панических атак и др.) при резком переходе из лежачего положения в сидячее или стоячее, или из сидячего в стоячее, с наличием или без наличия объективно значительных изменений артериального давления в любую сторону или значительных изменений ЧСС [1].

\section{Клиническая симптоматика ортостатической гипотензии в психиатрии}

Классическое врачебное представление о симптоматике ОГ подразумевает пациента, который предъявляет жалобы на возникающее при резком переходе из лежачего положения в сидячее или стоячее или из сидячего 
в стоячее головокружение, нередко тахикардию, слабость, шум, звон или свист в ушах, ощущение, что «закладывает уши», ощущение «мушек», «звёздочек» или «потемнения» в глазах (вплоть до иногда описываемых пациентами состояний «временной потери зрения или слуха» на несколько минут), ощущение «отсутствия опоры под ногами», шаткости и неустойчивости походки, нарушения координации движений, падения, обмороки [4].

При измерении показателей артериального давления в лежачем и сидячем или стоячем положении у такого пациента выявляется снижение САД при переходе из лежачего положения в сидячее или стоячее, или из сидячего в стоячее более чем на 20 мм.рт.ст., или снижение ДАД более чем на 10 мм.рт.ст., или же неадекватное повышение ЧСС более чем на 30 уд/ мин при сохранении нормальных цифр артериального давления или его незначительном изменении [4].

Однако симптомы ОГ могут и не быть классическими, или же могут внешне отсутствовать («бессимптомная» ОГ). Это, однако, не означает отсутствия вреда от этого состояния. Показано, что среди пациентов, у которых ортостатическое снижение САД превышает 60 мм.рт.ст., около $33 \%$ не знают об этом, так как не испытывают каких-либо симптомов, а ещё у 25\% симптомы ОГ атипичны [5].

Так, например, вместо ортостатического головокружения может наблюдаться ортостатическая головная боль (отражающая в данном случае ухудшение кровоснабжения мозговых оболочек, мышц скальпа и шеи), иногда упорная, не снимаемая обычными анальгетиками, но могущая самостоятельно купироваться при обратном переходе в лежачее положение или при приёме некоторых антимигренозных препаратов, обладающих симпатомиметическими или венотонизирующими свойствами (что порой приводит к ошибочному диагнозу мигрени). Может наблюдаться патологическое чувство усталости или повышенная утомляемость, плохая переносимость высоких температур внешней среды, физической нагрузки или сексуальной активности [5].

У пациентов с ОГ может также наблюдаться боль в затылке и/или в шее (особенно в задней её части), усиливающаяся или возникающая именно при переходе из лежачего положения в стоячее или сидячее или из сидячего в стоячее, и нередко ошибочно приписываемая «шейному остеохондрозу» или «дегенеративным изменениям в позвоночнике». Также может наблюдаться боль в мышцах плечевого пояса, грудной клетки, спины, верхних частях рук, иногда ошибочно принимаемая за «плечелопаточный периартрит», «синдром передней лестничной мышцы» и т. п. Действительной же 
причиной боли в этом случае является ухудшение кровоснабжения мышц верхней половины тела и межпозвонковых дисков при вставании [6, 7].

Другими частыми «атипичными» проявлениями ОГ являются желудочно-кишечные симптомы, напоминающие синдром раздражённого кишечника (СРК) или функциональную диспепсию (ФД), и также возникающие или усиливающиеся именно при переходе в ортостатическое положение: тошнота, урчание в животе, позывы в туалет и т. д. [8,9].

Поскольку ОГ и ОТ действительно чаще возникают у лиц с тревожными состояниями, неврозами, с наличием СРК и/или ФД, то эти симптомы и их связь с ортостатическим положением тела могут оставаться нераспознанными или быть ошибочно приписаны самому наличию СРК, ФД или невроза, тревожного состояния. В действительности же их причиной служит ухудшение висцерального кровоснабжения, и в частности кровоснабжения ЖКТ, в ортостатическом положении, а также происходящие при переходе в это положение изменения перистальтики ЖКТ и ритма желудочного пейсмейкера, выброс катехоламинов и др. [9].

К атипичным проявлениям ОГ относятся также кожные симптомы: бледность кожи верхней половины тела, акроцианоз (нередко ошибочно принимаемый за синдром Рейно), кожный зуд, возникающие или усиливающиеся в ортостатическом положении. Нередко кожный зуд при этом приписывают «психогенному кожному зуду», а его связи с ортостатическим положением тела не придаётся должного внимания. Предполагается, что причиной возникновения кожного зуда при этих состояниях является спазм сосудов кожи, её локальная ишемизация, а также гиперкатехоламинемия [9].

Значительная часть пациентов с хронической ОГ также предъявляет жалобы на бессонницу или нарушения сна, беспокойный, поверхностный сон или кошмарные сновидения. Причиной этого также считают гиперкатехоламинемию и гиперкортизолемию, развивающиеся в результате контррегуляторных реакций на повторные эпизоды ОГ [9].

Могут наблюдаться также жалобы на «нехватку воздуха», «затруднение дыхания», «стеснение в груди». Могут наблюдаться боли за грудиной, отражающие тахикардию и ухудшение коронарного кровотока в ортостатическом положении [9].

Симптомами хронической ОГ могут быть также патологическая сонливость, вялость, адинамия (снижение двигательной активности). Так, в частности, показано, что значительный процент патологической дневной сонливости, наблюдаемый у пожилых пациентов, а также у пациентов с такими заболеваниями, как нарколепсия, БА, БП, ДТЛ, связан на самом 
деле не с нейромедиаторными нарушениями, а с нераспознанной ОГ и с вызываемым ею ухудшением кровоснабжения ЦНС [10].

В контексте психиатрии важно то, что патологическая сонливость, вялость, адинамия или апатия, заторможенность, вызываемые именно ОГ, могут быть ошибочно спутаны с проявлениями седативного действия лекарств, или с проявлениями депрессии, или с проявлениями апато-абулической негативной симптоматики, с проявлениями ЭПС (лекарственного паркинсонизма), с ухудшением течения деменции и т. д. [3].

Это, в свою очередь, может привести к неверной тактике лечения, например, к повышению дозы АД или АП при депрессивных состояниях или при психозах, или к повышению дозы донепезила при дементных состояниях, вместо мер по коррекции ОГ. А это может привести к усугублению проблемы ОГ и вызванных ею симптомов. Возникает ятрогенный патологический порочный круг, подобный тому, который возникает в случаях, когда врач ошибочно расценивает акатизию как «тревогу», «психомоторное возбуждение» или «ухудшение течения психоза», а сенсорный компонент акатизии - как «сенестопатии», и увеличивает дозу АП или АД, вместо коррекции акатизии [3].

Кроме того, ОГ, так же, как и любой другой ПЭ, возникающий при применении ПФТ, например, такой, как снижение либидо или развитие ЭПС, способна снижать комплаентность пациентов к лечению, и даже может приводить к полному отказу от лечения и к развитию страха перед лечением [11].

Важно и то, что даже, казалось бы, «бессимптомная» ОГ может приводить к развитию клинически значимых КН, к ухудшению памяти, настроения и психоэмоционального состояния, к усилению проявлений депрессии и/или тревожности, к снижению концентрации внимания - причём эти симптомы могут быть единственными симптомами «бессимптомной» ОГ [3, 12].

\section{Диагностика ортостатической гипотензии}

Диагностика ОГ основывается на тщательном изучении анамнеза и жалоб пациента, включая упомянутые выше «атипичные» жалобы (ортостатические желудочно-кишечные жалобы, ортостатический кожный зуд, ортостатические головные боли, боли в шее, спине, плечелопаточном поясе, грудной клетке, патологическая сонливость, вялость, слабость, утомляемость и др.) [5].

Диагностике ОГ помогает также учёт и выявление возможных этиопатогенетических факторов и факторов риска, могущих послужить причиной развития ОГ (гиповолемия, отказ от еды и питья, тошнота, рвота, 
понос, обильное потоотделение, обильный диурез, недавнее начало ПФТ или гипотензивной терапии, высокие дозы психотропных или гипотензивных препаратов, быстрое наращивание их доз, комбинированная терапия, наличие коморбидных заболеваний, ассоциирующихся с риском возникновения ОГ независимо от проводимой ПФТ, таких, как СД, ГБ, ХСН, ИБС, автономная нейропатия, синдром Шая-Дреджера, БА или БП, РС и др., высокая температура внешней среды), а также прямое измерение артериального давления и ЧСС в покое лёжа, сидя и стоя [5].

При этом следует учитывать, что ортостатическое снижение артериального давления или ортостатическое повышение ЧСС может быть отсроченным и проявиться не сразу после перехода в стоячее или сидячее положение, а спустя несколько минут или даже десятки минут. Поэтому важно измерить артериальное давление и ЧСС несколько раз, с интервалами в 1-3, 5, 10 и 15 минут после изменения положения тела, особенно в сомнительных случаях [5].

Диагностике субклинических форм ОГ помогает так называемый tilttable test - измерение артериального давления и ЧСС при изменении положения стола, на котором фиксирован пациент, а также внимательный расспрос пациента о том, как влияют на переносимость им ортостатической нагрузки такие известные провоцирующие ОГ факторы, как недавний приём пищи, физическая нагрузка, сексуальная активность, приём горячей ванны или душа [5].

Иногда для диагностики субклинических форм ОГ требуется измерение уровней катехоламинов, ренина, альдостерона и кортизола в лежачем и стоячем положениях, и сопоставление величины этих изменений с физиологически нормальными изменениями [5].

\section{Дифференциальная диагностика осложнений ортостатической гипотензии}

В психиатрической практике осложнения ОГ необходимо дифференцировать с другими патологическими состояниями, способными вызывать сходную симптоматику. В частности, ОГ и вызываемую ею патологическую сонливость, вялость и адинамию необходимо дифференцировать от проявлений седативного действия лекарств, вызываемые ею КН и депрессивные нарушения - от проявлений собственно депрессии, деменции или СДВГ, соответственно, вызываемое ею ухудшение моторных функций - от проявлений БП или ЭПС, вызываемую ею тревожность - от проявлений тревожных расстройств (ТР) и др. [3]. 
Вызываемые ОГ и ОТ ортостатические головокружения и ортостатические панические атаки могут потребовать дифференциальной диагностики с паническим расстройством (ПР), расстройствами вестибулярного аппарата (доброкачественным позиционным головокружением, вестибулярным нейронитом и др.) [3].

Вызываемые ОГ и связанным с нею ухудшением висцерального кровотока желудочно-кишечные симптомы (тошнота, урчание в животе, боли в животе и др.) могут потребовать дифференциальной диагностики с СРК, ФД и другими функциональными расстройствами ЖКТ [9].

Вызываемые ОГ и связанным с нею ухудшением кровоснабжения мышц различные ортостатические болевые синдромы (головные боли, боли в шее, спине, плечелопаточном поясе, грудной клетке) могут потребовать дифференциальной диагностики с такими болевыми синдромами, как хроническая головная боль напряжения (ХГБН), мигрень, боли, связанные с шейным остеохондрозом или другими дегенеративными изменениями позвоночника, плечелопаточный периартрит, ИБС и др. [9].

Дифференциальной диагностике в подобных случаях помогает, во-первых, часто довольно чётко прослеживающаяся связь проявления этих симптомов именно с изменением положения тела, во-вторых, более частое проявление этих симптомов с утра (когда ортостатическая толерантность ниже), а также после воздействия таких провоцирующих факторов, как приём пищи, высокая температура внешней среды, физическая нагрузка или сексуальная активность, в сочетании с переменой положения тела, и, в-третьих, прямое измерение артериального давления в покое лёжа и сидя либо стоя, причём именно в моменты проявления симптомов [9].

В сомнительных случаях дифференциальной диагностике помогает пробное лечение, направленное на устранение симптомов ОГ (например, увеличение потребления воды и поваренной соли, ношение компрессионных гольфов или чулков, приём препаратов калия, кальция и магния, флудрокортизона и др.). Исчезновение подозрительных «атипичных» симптомов при пробном лечении служит доказательством их ортостатической природы (терапия ex juvantibus) [9].

\section{Осложнения ортостатической гипотензии}

\section{Осложннения со стороны центральной нервной системы}

Показано, что ОГ может усиливать проявления синдрома дефицита внимания (СДВГ), причём как у детей, так и у подростков и взрослых. Она может также усиливать проявления нарколепсии, другого типичного 
заболевания молодых людей. Эти два заболевания (СДВГ и нарколепсия) вообще часто бывают коморбидны с хронической ОГ, вероятно вследствие того, что при обоих заболеваниях, наряду с уменьшением дофаминергической и норадренергической активности в префронтальной коре, отмечается также уменьшение потока симпатических импульсов из ЦНС на периферию [13, 14].

Существует даже теория, согласно которой положительное действие психостимуляторов - ПС (модафинил, метилфенидат, амфетамин), атомоксетина и других ингибиторов обратного захвата (O3) норадреналина, или центральных $\alpha_{2}$ адреностимуляторов (клонидин, гуанфацин) при СДВГ и нарколепсии лишь отчасти связано с их центральным действием, и что важное значение в их механизме действия при этих состояниях имеет также их способность уменьшать проявления ОГ и повышать мозговой кровоток на фоне ортостатической нагрузки при применении их в терапевтических дозах $[13,14]$.

Ухудшая кровоснабжение базальных ганглиев мозга, ОГ приводит к усилению ЭПС при БП и при других заболеваниях, протекающих с паркинсоническим синдромом (например, при ДТЛ), к снижению двигательной активности пациента, и значительно ухудшает прогноз при этих заболеваниях. Она может даже служить предиктором грядущего ухудшения моторных и когнитивных функций пациентов с БП или ДТЛ [15].

За счёт аналогичного механизма (ухудшения кровоснабжения базальных ганглиев) ОГ способна усиливать ЭПС, вызываемую приёмом АП [16, 17]. Согласно одной из теорий, именно этим, а вовсе не неблагоприятными фармакокинетическими взаимодействиями (повышением концентрации АП в крови) или повышением суммарного процента оккупации $\mathrm{D}_{2}$ рецепторов нигростриарной системы, объясняется тот давно известный факт, что сочетание мощного, высокопотентного АП (такого, как галоперидол или трифлуоперазин), вызывающего выраженные ЭПС, с низкопотентным седативным АП типа хлорпромазина или клозапина, вызывающим выраженную $\alpha_{1}$ адренергическую блокаду и связанную с ней ОГ, особенно часто приводит к развитию тяжёлых ЭПС [17].

Показано, что даже небольшая, субклиническая (то есть не проявляющаяся какими-либо выраженными «классическими» симптомами, «бессимптомная〉 или малосимптомная) ОГ достоверно приводит к ухудшению когнитивного функционирования пациентов, к ухудшению памяти и интеллектуальной продуктивности, к развитию астении (физической слабости), к повышенной утомляемости и хронической усталости, к апатии, 
адинамии (снижению физической активности), к снижению энергии и мотивации, ухудшению концентрации внимания, к усилению депрессии и ощущения беспомощности, к повышению тревожности $[3,18,19]$.

Также показано, что хроническая ОГ является фактором риска развития депрессий позднего возраста, и может быть ранним симптомом или предиктором их развития [20]. Ранее считалось, что ОГ при БП или таких деменциях, как БА, ДТЛ, возникает в достаточно поздних стадиях, на фоне прогрессирования болезни и развития выраженной автономной нейропатии. Сегодня же известно, что «немоторные» или «некогнитивные» симптомы, такие, как депрессия или хроническая ОГ, могут быть первыми симптомами и даже предвестниками развития БП или БА [21].

Показано, что ОГ является важным фактором риска когнитивных и эмоциональных нарушений (депрессии, тревожности) вовсе не только у пациентов пожилого и старческого возраста, но и у детей и подростков, и у людей молодого и среднего возраста. Таким образом, этот риск универсален для всех возрастных групп [3].

Возникающие при ОГ отсроченные контррегуляторные прессорные реакции, такие, как выброс катехоламинов, вазопрессина, АКТГ и кортизола, способны ухудшать течение психических заболеваний [3]. Как сама ОГ и вызываемое ею ухудшение мозгового кровотока, так и возникающие при ней отсроченные контррегуляторные нейроэндокринные реакции способны снижать эффективность ПФТ (в частности, эффективность лечения методами ПФТ депрессивных, тревожных состояний, деменций, психозов, СДВГ) и вызывать резистентность к ПФТ (полную или частичную) [3].

Однако существует и другая точка зрения, согласно которой ОГ самa по себе непосредственно не вызывает резистентность к ПФТ, а лишь служит «прокси-симптомом», своеобразным маркером каких-то других неблагоприятных процессов, вызывающих ОГ и могущих служить истинной причиной резистентности к ПФТ. Согласно этой точке зрения, появление ОГ может быть маркером наличия гиповолемии, или тех или иных нутритивных дефицитов, с ней ассоциирующихся (например, гипонатриемии, дефицитов железа, витаминов $\mathrm{C}, \mathrm{B}_{1}, \mathrm{~B}_{6}, \mathrm{~B}_{12}, \mathrm{D}$, калия, кальция или магния и др.), или маркером ухудшения течения коморбидного СД и связанной с ним диабетической автономной нейропатии, или маркером прогрессирования БП, РС, ХСН, ГБ, психического заболевания (например, депрессии), деменции того или иного вида и т. п. [3].

Третья точка зрения сводится к тому, что эти два события - появление симптомов ОГ и ухудшение психического состояния или ухудшение тече- 
ния коморбидных соматических и неврологических заболеваний - всего лишь коинцидентальны (совпадают во времени, но не связаны причинноследственной связью) [3].

Сами же Л. Перлмутер с соавторами, как и мы сами, авторы настоящей статьи, однако, придерживаются той точки зрения, что ОГ может непосредственно ухудшать течение психического заболевания и вышеупомянутых коморбидных соматических и неврологических патологий, и может непосредственно вызывать резистентность к ПФТ или снижение её эффективности [3].

\section{Осложнения со стороны эндокринной системы}

Вызываемые ОГ отсроченные контррегуляторные прессорные реакции, в частности, выброс катехоламинов и кортизола, могут приводить к ухудшению течения СД [3].

\section{Осложнения со стороны опорно-двигательного аппарата}

Уже достаточно давно было известно о том, что ОГ является фактором риска падений, а также одним из важнейших факторов риска бытового травматизма, гематом и ушибов, ранений мягких тканей, вывихов суставов и переломов костей, включая перелом шейки бедра и компрессионные переломы позвоночника, способные привести к длительной иммобилизации и инвалидизации пациента [22].

Особенно часто такие переломы костей на фоне ОГ и вызванных ею падений встречаются у пожилых пациентов или у пациентов, по тем или иным причинам имеющих остеопороз, пониженную минерализацию костей или повышенную склонность к патологическим переломам костей (например, метастазы злокачественных опухолей в кости) [23].

Между тем, пациенты с психическими заболеваниями тоже относятся к группе повышенного риска развития остеопороза, а следовательно, и патологических переломов, вызванных падениями на фоне ОГ [23].

\section{Сердечно-сосудистые осложнения}

Давно известно, что ОГ является фактором риска таких опасных сердечно-сосудистых осложнений, как ОИМ, острое нарушение мозгового кровообращения (ОНМК) или ишемический инсульт (ИИ) на её фоне, особенно у пожилых людей и у лиц, имеющих коморбидные сердечно-сосудистые заболевания (СС3), или иные предрасполагающие к сердечно-сосудистым катастрофам заболевания, такие, как СД, дислипидемия [24]. 
Кроме того, хроническая ОГ и вызываемые ею отсроченные контррегуляторные прессорные реакции могут ухудшать течение ГБ, ИБС, ХСН, и быть причиной сердечных аритмий. Хроническая ОГ ассоциируется также с повышенным риском внезапной смерти [24].

\section{Факторы риска развития ортостатической гипотензии у пациентов с психическими заболеваниями}

Показано, что наиболее важным в профилактике ОГ и её осложнений мероприятием является правильная стратификация пациентов на группы риска в соответствии с индивидуальным риском возникновения ОГ у конкретного пациента, и планирование как собственно лечения (психиатрического или гипотензивного) с учётом этого риска, так и превентивных мер для предупреждения ОГ в угрожаемых группах пациентов [3].

В свете этого для психиатра весьма важно знать, каковы известные факторы риска для развития этого осложнения.

\section{Факторы риска, связанные \\ с демографическими характеристиками пациента Возраст}

К развитию ОГ особенно предрасположены лица пожилого и старческого возраста [3].

Однако риск развития ОГ и связанных с нею КН и эмоциональных нарушений повышен также у детей и подростков, и у молодых людей (то есть в раннем постпубертатном периоде). Происходит это в связи с функциональной незрелостью сердечно-сосудистой и эндокринной систем, неустойчивостью нейрогуморальной и вегетативной регуляции сосудистого тонуса в детском, подростковом, юношеском и молодом (раннем постпубертатном) возрасте [3].

Лица среднего возраста, при прочих равных условиях, при воздействии одинаковых неблагоприятных факторов, имеют относительно меньший по сравнению с другими возрастными группами (как по сравнению с детьми, подростками и молодыми людьми, так и по сравнению с пожилыми и стариками) риск развития ОГ и связанных с нею КН и эмоциональных нарушений [3].

\section{Пол}

Женский пол является одним из важных факторов, предрасполагающих к развитию ОГ и связанных с нею КН и эмоциональных нарушений [25].

Предполагается, что это связано с влиянием гормонов, так как наибольшие гендерные различия в предрасположенности к развитию ОГ наблюдаются у молодых женщин по сравнению с молодыми мужчинами, в 
то время как в постменопаузальном периоде, по сравнению с мужчинами сопоставимого возраста, эти различия сглаживаются [25].

Другими важными факторами, могущими играть роль в повышенной предрасположенности молодых женщин к развитию ОГ по сравнению с молодыми мужчинами, называются относительно меньшая масса тела женщин и в частности меньшая мышечная масса, более низкое расположение центра масс тела (в силу чего гравитация вызывает у них более сильное ортостатическое депонирование крови), меньший объём циркулирующей крови (ОЦК), высокая распространённость среди менструирующих женщин железодефицитной анемии (ЖДА) или дефицита тканевого железа (в том числе скрытого, субклинического) и нарушений функции щитовидной железы (в том числе субклинических), более высокая у женщин частота варикозного расширения вен нижних конечностей и геморроидальных вен (что приводит к уменьшению венозного возврата), а также более высокая по сравнению с мужчинами частота развития таких ассоциирующихся с ОГ психических заболеваний, как депрессивные и тревожные состояния, нервная анорексия, нервная булимия [25].

Особенно предрасположены женщины к развитию ОГ в дни менструации и в дни, непосредственно ей предшествующие, и особенно при наличии обильных или болезненных менструаций или синдрома предменструального напряжения [26].

Важно отметить, что, несмотря на то, что менопауза сглаживает гендерные различия в частоте ОГ, переходный климактерический период, наоборот, сопровождается значительным повышением риска её возникновения, а эстрогенная гормонозаместительная терапия (ГЗТ) в этот период снижает риск развития ОГ [27].

Угрожаемым по развитию ОГ периодом в жизни женщины является также период беременности [28]. Этот риск особенно велик у беременных с крупным плодом или многоводием, многоплодной беременностью (вследствие увеличенного депонирования крови в компартменте матки и плаценты), у беременных с выраженным ранним токсикозом (вследствие потерь жидкости с рвотой, дегидратации и нарушений электролитного обмена) и с такими осложнениями беременности, как гестационный СД, дефицит железа, фолатов или витамина $\mathrm{B}_{12}$ и др. [28].

Ещё больше риск развития ОГ в раннем послеродовом периоде, особенно при значительной кровопотере в родах. Риск развития ОГ также повышен у тех родильниц, у которых развивается послеродовая депрессия или послеродовый психоз, по сравнению с теми родильницами, у которых послеродовый период протекает нормально [29]. 


\section{Раса и этническое происхождение}

Хорошо известно, что различные СС3, и в частности ГБ, ОНМК, ИБС, хотя и встречаются у представителей всех рас и этносов, но имеют значительные межэтнические вариации. Известно также, что у представителей разных рас и этносов различна и реакция на гипотензивные лекарства. Так, у представителей чёрной расы ГБ, ОНМК и ИБС встречаются достоверно чаще. В то же время у них более эффективны диуретики и $\beta$-блокаторы, по сравнению с представителями белой расы [30].

В свете этого представляет большой интерес вопрос о том, не является ли предрасположенность к развитию ОГ также зависящей от расы и этнического происхождения. Показано, что у представителей белой расы, по сравнению с представителями чёрной расы, ОГ встречается более чем вдвое чаще. Этот эффект сохраняется после введения поправок на различия в частоте встречаемости ССЗ, в применяемых дозах гипотензивных препаратов и в средней массе тела (лица чёрной расы более склонны к ожирению) [30].

В другом исследовании также показано, что представители национальности банту более устойчивы к воздействию ортостатического стресса, чем представители белой расы. Этот эффект также сохранился после введения статистических поправок на массу тела, различия в физической тренированности и др. [31].

Таким образом, можно заключить, что принадлежность к белой расе является одним из факторов риска развития ОГ.

В то же время в одном из исследований получены противоположные данные, согласно которым, афроамериканцы более предрасположены к развитию ОГ (наряду с большей предрасположенностью к ГБ и другим СС3), чем белые американцы [32].

Однако в этом исследовании также была обнаружена корреляция между частотой развития ОГ и уровнем образования и социально-экономическим статусом (ОГ чаще встречалась у бедных, безработных и у лиц с образованием меньше полного среднего - 12 классов, а такие лица статистически чаще встречаются среди лиц чёрной расы в США). Из этого авторы исследования сделали вывод, что более высокая предрасположенность темнокожих американцев к развитию ОГ по сравнению с белыми американцами связана не с влиянием собственно расовых (генетических) факторов, а с более значительным социально-экономическим стрессом, который испытывают темнокожие граждане, и более высоким уровнем дискриминации, сохраняющимся несмотря на все усилия по ее преодолению [32]. 
Уровень образования и социально-экономический статус

Показано, что уровень образования и социально-экономический статус являются независимыми факторами риска развития ОГ. А именно, у бедных, безработных и у лиц с низким уровнем образования (менее законченного среднего) - которые, как правило, мало зарабатывают, ОГ встречается достоверно чаще. Авторы этого исследования связывают этот факт с более высоким уровнем психоэмоционального стресса, которому подвергаются бедные, безработные и лица с низким уровнем образования, а также, возможно, с недоеданием или плохим состоянием питания, отсутствием денег на своевременную и качественную диагностику и медицинскую помощь [32].

Между тем известно, что серьёзные психические заболевания, например, депрессия, шизофрения, часто ассоциируются с бедностью, отсутствием работы, низким социально-экономическим статусом [33].

Другие характеристики паџиента (рост, масса тела)

Пациенты высокого роста более предрасположены к развитию ОГ, чем пациенты более низкого роста, вероятно вследствие действия такого физического фактора, как большая работа сердца «против силы тяжести» при более высоком росте [34].

Избыточная масса тела или ожирение также сопряжены с пониженной ортостатической толерантностью и с риском развития ОГ. Предполагается, что это может иметь место вследствие действия таких факторов, как необходимость в дополнительной работе сердца для обеспечения адекватного кровоснабжения большой массы тела, повышенная частота ГБ, СД 2-го типа или атеросклероза сосудов у пациентов с ожирением (все эти заболевания предрасполагают к развитию ОГ), повышенная секреция инсулина, лептина и провоспалительных цитокинов и др. [35].

В то же время пониженная масса тела, худоба, истощение или недавняя значительная потеря массы тела также являются важными факторами риска, предрасполагающими к развитию ОГ [30, 36].

Наименее предрасположены к развитию ОГ пациенты с нормальной массой тела.

\section{Факторы риска, связанные с злоупотреблением психоактивными веществами}

Многие пациенты с психическими заболеваниями злоупотребляют алкоголем. Между тем алкоголь, особенно в сочетании с психотропными, гипотензивными и сосудорасширяющими препаратами, является одним из известных провокаторов и потенциаторов ОГ, и значительно ухудшает переносимость ортостатической нагрузки $[37,38]$. 
Показано, в частности, что именно алкоголь и психотропные препараты, и особенно их сочетание, в большей мере, чем гипотензивные, сосудорасширяющие или антиаритмические препараты, является фактором риска развития ОГ и связанных с нею падений, травм, переломов и ушибов, особенно у пациентов пожилого и старческого возраста [39].

Многие пациенты с психическими заболеваниями также злоупотребляют каннабиноидами, как природными (марихуана, гашиш), так и синтетическими («спайс»). Между тем, острое воздействие каннабиноидов нередко приводит, наряду с проявлениями симпатоадреналовых реакций (тахикардия, артериальная гипертензия, усиление тревожности, провокация панических атак), также и к проявлениям ОГ [40].

Хроническое же воздействие каннабиноидов сопровождается уменьшением или извращением симпатического барорефлекса, снижением активности симпатического отдела нервной системы и повышением активности парасимпатического её отдела, что также может сопровождаться повышением склонности к ортостатической гипотензии [41].

Этот эффект частично компенсируется задержкой жидкости и увеличением объёма плазмы на фоне хронического употребления каннабиноидов. Теоретически это может повышать толерантность к ортостатической нагрузке. Но это наблюдается не у всех пациентов, хронически злоупотребляющих каннабиноидами. Поэтому эффекты, связанные с влиянием на соотношение парасимпатической и симпатической активностей, могут преобладать [41].

Злоупотребление опиатами и опиоидами, а также различными депрессантами ЦНС (например, бензодиазепинами, барбитуратами) также способно вызвать развитие ОГ, причём как на фоне действия самого вещества (вследствие гипотензии, связанной со снижением потока симпатических импульсов из ЦНС к периферии), так и на фоне синдрома отмены (СО), нередко протекающего с рвотой, поносом, обильным потоотделением и, как следствие, гиповолемией и дефицитом электролитов [41].

Злоупотребление кокаином, амфетамином и другими ПС, включая кофеин и никотин, также предрасполагает к развитию ОГ на фоне СО от ПС, поскольку при этом развивается своеобразная «относительная симпато-адреналовая недостаточность» [41].

\section{Иммобилизация}

\section{и физическая детренированность как фактор риска}

Ещё одним важным фактором, предрасполагающим пациентов с психическими заболеваниями к развитию ОГ, является нередко наблюдаемая у них детренированность сердечно-сосудистой системы вследствие 
снижения физической активности или вследствие длительного лежания в постели, связанного как с ПЭ от ПФТ (сонливость, вялость, апатия, заторможенность, седация, миорелаксация, лекарственный паркинсонизм), так и с болезненными проявлениями самой депрессии, апато-абулических дефектных состояний, с депрессивным или кататоническим ступором и др. [42].

Длительное лежание в постели или физическая детренированность известный провоцирующий фактор развития ОГ не только у пациентов с психическими заболеваниями, но и у здоровых добровольцев в эксперименте, и у пациентов с соматическими заболеваниями [43].

В равной мере это относится к пациентам, подвергнутым вынужденной иммобилизации вследствие острого психомоторного возбуждения или агрессивности, или вследствие травм, переломов, вывихов [42].

\section{Факторы риска, связанные с самим психическим заболеванием}

Общие факторы риска, связанные с психическим заболеванием

У пациентов с психическими заболеваниями, особенно стационарного уровня (то есть, поступающих в стационары в связи с тяжёлым или острым психическим заболеванием), нередко наблюдаются исходная гиповолемия и дегидратация, связанная с неадекватным, недостаточным приёмом жидкостей или полным отказом от питья, а также с нередко наблюдаемым на фоне психических расстройств снижением нормальной реакции жажды в ответ на гиповолемию, гипотензию или повышение осмоляльности плазмы, с изменениями в секреции катехоламинов, вазопрессина и кортизола (нередкое при психозах, тревожных состояниях, депрессиях повышение базальной секреции катехоламинов, вазопрессина, кортизола и АКТГ сопровождается уменьшением выброса катехоламинов, вазопрессина и кортизола в ответ на ортостатическую нагрузку) [42].

Это, разумеется, предрасполагает эту категорию пациентов к развитию ОГ.

Кроме того, у пациентов с психическими заболеваниями, особенно стационарного уровня, может также наблюдаться выраженное снижение аппетита (гипорексия), вплоть до полного отказа от еды (анорексии). Это может приводить к развитию гипонатриемии, гипокалиемии и гипогликемии, других нутритивных дефицитов, к снижению осмоляльности плазмы и ОЦК, снижению сократимости миокарда и к уменьшению нормальной прессорной реакции сосудов на выделение катехоламинов и вазопрессина при ортостатической нагрузке [42].

У пациентов с психическими заболеваниями может наблюдаться и гипокальциемия, например, вследствие длительного отказа от еды, рво- 
ты, использования слабительных, диуретиков и т. д. (как, скажем, при нервной анорексии, булимии), а также вследствие вызываемых гиперкортизолемией и гиперкатехоламинемией повышенных потерь кальция с мочой [44].

Между тем известно, что гипокальциемия также является важным фактором риска развития ОГ, особенно в тех случаях, когда гипокальциемия развивается достаточно остро [45]. Механизмы, которыми гипокальциемия вызывает ОГ, многообразны и включают в себя снижение нормальной гиперренинемической реакции почек на ортостатический стресс, снижение сердечного выброса, снижение активности симпатических нервных окончаний и секреции катехоламинов, уменьшение чувствительности сосудистой стенки к прессорным стимулам и др. [45].

Тот же комплекс причин может приводить и к развитию гипомагнеземии. Между тем, хотя фармакологические дозы препаратов магния, как известно, оказывают выраженное гипотензивное действие - физиологическая концентрация магния крайне важна для поддержания нормального артериального давления. Это связано, в частности, с тем, что ионы магния критически необходимы для работы G-белков, в том числе белков, передающих внутрь клетки сигнал с адренорецепторов и рецепторов вазопрессина. Поэтому дефицит магния тоже может предрасполагать к развитию ОГ [45].

Дефицит железа, в том числе дефицит тканевых запасов железа (не проявляющийся классической ЖДА), также часто встречается у пациентов с психическими заболеваниями, вследствие, например, пониженного питания или анорексии, потерь железа при кровоточивости десен или слизистой желудка, геморроидальных и менструальных кровотечениях и др. [44].

Между тем известно, что дефицит железа (как явный, сопровождающийся ЖДА, так и скрытый) предрасполагает к нарушению ортостатической толерантности и к развитию ОГ [46]. Особенно часто ассоциация между дефицитом железа и ОГ наблюдается у подростков и молодых людей, прежде всего девушек, а также у пациентов с так называемым «синдромом хронической усталости» (СХУ) [46].

К развитию ОГ могут предрасполагать и некоторые другие нутритивные дефициты, например, $\mathrm{B}_{12}$ - или фолат-дефицитная анемия, нейропатии, связанные с дефицитом $\mathrm{B}_{1}$ или $\mathrm{B}_{6}$, дефицит цинка, дефицит меди и связанное с ним нарушение биосинтеза катехоламинов и др. Всё это тоже с повышенной частотой встречается у пациентов с психическими заболеваниями [46]. 
Тяжесть психического состояния как фактор риска

Особенно высокая степень риска развития ОГ наблюдается у пациентов, у которых исходное психическое состояние было особенно острым или тяжёлым, независимо от присутствия или отсутствия таких факторов, как исходная дегидратация и гиповолемия, электролитные нарушения, нутритивные дефициты, отказ от еды и питья, преимущественно постельный режим [42].

Возможно, это объясняется особой выраженностью нейроэндокринных нарушений и, в частности, нарушений функции осей «гипоталамус-гипофиз-надпочечники» (ГГН) и «ренин-ангиотензин-альдостерон» (PAAC), высокой базальной гиперкортизолемией и гиперкатехоламинемией и снижением адаптивной реакции этих систем на ортостатическую нагрузку именно в этой тяжёлой и острой подгруппе пациентов [42].

Однако есть и другое объяснение, согласно которому это наблюдение является ятрогенным артефактом. Этот артефакт, как предполагается, связан с тем, что пациенты, находящиеся в особенно тяжёлых или острых состояниях, с большей вероятностью получат изначально высокие дозы сильнодействующих психотропных препаратов (мощных АП, ТЦА, высокопотентных бензодиазепинов), что у них дозы психотропных препаратов будут наращиваться быстрее, что эти пациенты с большей вероятностью получат лекарства именно в форме парентерального введения, что эти пациенты с большей вероятностью будут подвергнуты физической иммобилизации на вязках, или таким методам интенсивной биологической терапии, как ЭСТ, а ранее также АКТ или ИКТ, при которых также существует риск развития ОГ [42].

\section{Факторы риска, связанные с коморбидными соматическими заболеваниями}

Мы не будем здесь останавливаться на таких понятных факторах риска развития ОГ в психиатрии, как наличие у пациента коморбидного общесоматического, неврологического или эндокринного заболевания, которое само по себе может сопровождаться ОГ (например, СД, ГБ, ХСН, последствия ОИМ, БП, РС, недостаточность коры или мозгового слоя надпочечников, автономная нейропатия, гипотиреоз, гипертиреоз, синдром Шая-Дреджера, паранеопластический синдром при злокачественных опухолях, анемия и т. д.).

Однако не все знают, что фактором риска развития ОГ на фоне психического заболевания является также присоединение какой-либо интеркуррентной инфекции. Даже сравнительно нетяжёлая и «банальная» инфекция, такая, как ОР3, острый тонзиллит, синусит или инфекция мочевых путей (банальный бактериальный уретрит или цистит), способна рез- 
ко снизить переносимость ортостатической нагрузки и вызвать появление симптомов ОГ даже у пациентов, ранее хорошо переносивших ПФТ [42].

Острые инфекционные заболевания - известный фактор риска развития ОГ и вегетативной дисфункции даже у исходно здоровых лиц. Иногда это приводит к тяжёлым осложнениям. Так, описан случай 15-летней девочки, у которой на фоне гриппа А развилась острая вегетативная нейро- и ганглиопатия, приведшая к тяжёлой ОГ и повторным синкопальным эпизодам, что потребовало внутривенного введения глюкокортикоидов, симпатомиметиков, вазопрессина и антигриппозного иммуноглобулина [47].

В другом случае тяжёлая ОГ и автономная нейропатия развилась у молодой женщины на фоне краснухи, которая, как известно, в отличие от кори обычно переносится взрослыми достаточно легко (но не в этом случае). В этом случае также потребовалось внутривенное введение глюкокортикоидов, симпатомиметиков, вазопрессина и нормального человеческого иммуноглобулина [48].

Описан случай тяжёлой ОГ с повторными обмороками у пожилого мужчины с хроническим отитом, хроническим синуситом и очагом инфекции в мягких тканях возле основания черепа, разрешившийся после успешного лечения инфекции [49]. Предположительно, причиной этого явилось инфекционное поражение каротидных синусов [49].

Часто встречается ОГ также при различных острых и хронических вирусных инфекциях, особенно нейротропных. Описано её возникновение при герпетической инфекции, например при опоясывающем лишае, при герпетическом энцефалите, при вызванном герпесом парезе лицевого нерва, при ЦМВ-инфекции, при инфекции вирусом Эпштейна-Барр (инфекционном мононуклеозе), при клещевом энцефалите и его последствиях, при гепатитах В и C, особенно на фоне лечения гепатита С интерферонами и рибавирином [50-55].

Роль же бактериальных септических инфекций, особенно стафилококковой, и связанного с этими инфекциями синдрома бактериально-токсического шока (БТШ) в развитии тяжёлой ОГ, известна давно [56].

Выраженная ОГ также часто встречается у пациентов, инфицированных ВИЧ, причём у этих пациентов может не быть явного СПИДа или СПИД-ассоциированного комплекса. Предполагается, что это может быть связано как с поражением ЦНС и развитием автономной нейропатии на фоне ВИЧ-инфекции, так и с изменениями цитокинового профиля, предрасполагающими к ОГ, или с нередко наблюдаемой у ВИЧ-инфицированных пациентов хронической диареей, потливостью и относительной дегидратацией [57]. 
Описан даже случай, когда именно ОГ оказалась первым симптомом ВИЧ-инфекции у пациента [58]. Ещё одной причиной предрасположенности к ОГ у ВИЧ-инфицированных пациентов является скрытая недостаточность коры надпочечников [59].

\section{Факторы риска, связанные с воздействием факторов внешней среды}

Важным фактором риска развития ОГ как у здоровых лиц, так и у пациентов с психическими заболеваниями, и у пациентов с СС3 и с расстройствами вегетативной регуляции различной этиологии (например, с СД и связанной с этим диабетической нейропатией, с БП, БА или ДТЛ, МСА, синдромом Шая-Дреджера), является высокая температура внешней среды, воздействие теплового стресса (например, проживание в жарком климате, особенно недавний переезд и незавершённость акклиматизации, жаркое время года в средней полосе, отсутствие кондиционирования в помещении, или воздействие горячего душа, горячей ванны, сауны или бани) [60].

Патофизиологические механизмы, за счёт которых тепловой стресс вызывает ухудшение ортостатической толерантности, включают в себя расширение периферических сосудов (прежде всего поверхностных сосудов кожи, но также и подкожной клетчатки и скелетных мышц) и усиление теплоотдачи, учащение дыхания и увеличение потерь воды в процессе дыхания, гипокапнию в результате усиленной вентиляции легких и вызываемое гипокапнией ухудшение кровоснабжения мозга, усиление потоотделения и вызываемую этим гиповолемию, гипонатриемию, гипокалиемию и иногда гипокальциемию, гипомагнеземию [60].

\section{Ортостатическая гипотензия \\ как побочный эффект психиатрического лечения Ортостатическая гипотензия \\ как побочный эффект психофармакотерапии}

Как известно, ОГ нередко возникает в процессе лечения многими психотропными препаратами. Особенно часто ОГ возникает в начале психотропной терапии или при быстром наращивании доз психотропных препаратов, при высоких их начальных или итоговых дозах, а также при наличии таких предрасполагающих факторов, как обезвоживание пациента, повышенная температура его тела, высокая температура внешней среды, те или иные электролитные нарушения и др. [61]. 
Разные психотропные препараты обладают разной способностью вызывать ОГ. Наиболее значимым фактором в определении способности того или иного психотропного препарата вызывать ОГ является наличие и выраженность у него $\alpha_{1}$-адреноблокирующей активности [62].

Ниже мы охарактеризуем различные группы психотропных препаратов по их способности вызывать ОГ и рассмотрим литературные сообщения о случаях ОГ на тех или иных психотропных препаратах.

\section{Антипсихотики}

Наибольшее значение в способности АП вызывать ОГ имеет их свойство блокировать центральные и периферические $\alpha_{1}$-адренорецепторы, выраженное в различной степени у большинства из них. Лишь немногие АП практически лишены этого свойства. Таковы, например, амисульприд и сульпирид, которые редко вызывают ОГ [62].

Однако проблему патогенеза ОГ при приёме АП не следует чрезмерно упрощать и сводить только лишь к их способности блокировать $\alpha_{1}$-адренорецепторы. Так, в частности, показано, что те дозы мощных, высокопотентных АП, которые обладают сравнительно слабым $\alpha_{1}$-адреноблокирующим действием, но сильным $\mathrm{D}_{2}$-блокирующим действием (например, галоперидола, трифлуоперазина), которые способны вызывать ЭПС, в такой же степени способны спровоцировать и проявления ОГ [17].

Предполагается, что механизм этого явления связан с «фармакологической денервацией» симпатоадреналовой части вегетативной нервной системы при снижении дофаминергической активности в вегетативных ядрах гипоталамуса. То есть, предполагается, что здесь задействован патофизиологический механизм, аналогичный механизму развития ОГ при «настоящей» БП [17].

В свете этого авторы выше процитированного обзора от 1992 года, как и авторы настоящей статьи, предостерегают от недооценки риска возникновения ОГ при применении мощных, высокопотентных АП, которые традиционно считаются «более безопасными» в этом плане. Они также предостерегают от использования чрезмерно завышенных доз высокопотентных АП. В частности, они указывают, что для большинства пациентов с первым эпизодом шизофрении, ранее не леченых, вполне достаточно доз порядка 5-10 мг/сут галоперидолового эквивалента - доз, редко вызывающих как тяжёлые ЭПС, так и выраженную ОГ [17].

Важное значение в патогенезе ОГ на фоне приёма АП имеет также способность многих АП, особенно низкопотентных, блокировать М-холи- 
норецепторы и $\mathrm{H}_{1}$-гистаминовые рецепторы. Показано, что М-холинергическая или $\mathrm{H}_{1-}$ гистаминергическая блокада снижает способность сосудов головного мозга адекватно реагировать на локальное выделение сосудорасширяющих веществ - ацетилхолина и гистамина - и дополнительно снижает ортостатическую толерантность [63].

На фоне уже имеющегося, вызванного $\alpha_{1}$-адреноблокадой, снижения системного артериального давления это дополнительное ухудшение церебрального кровотока, вызванное М-холиноблокирующим или $\mathrm{H}_{1}$-гистаминоблокирующим действием АП, особенно опасно [17].

Именно поэтому ОГ особенно часто возникает при применении низкопотентных АП, типа хлорпромазина, хлорпротиксена, клозапина, кветиапина. Большинство из них, наряду с сильными $\alpha_{1}$-адреноблокирующими свойствами, обладает также сильными $\mathrm{H}_{1}$-гистаминоблокирующими и/или М-холиноблокирующими свойствами [62].

Ещё чаще выраженная ОГ наблюдается при сочетании мощного $\mathrm{D}_{2}$-блокатора (например, галоперидола или трифлуоперазина) с низкопотентным седативным АП, обладающим мощными $\alpha_{1}$-адреноблокирующими, М-холиноблокирующими и $\mathrm{H}_{1}$-гистаминоблокирующими свойствами (например, хлорпромазина, хлорпротиксена, левомепромазина или клозапина). Такие сочетания были в своё время весьма популярны на Западе [17].

Ныне же большинство западных авторов предостерегают от использования подобных сочетаний в связи с усилением ПЭ (и в том числе ОГ и ЭПС), а также в связи с тем, что полинейролепсия, как показывают исследования, менее эффективна в купировании психоза, чем монотерапия одним АП, и пролонгирует пребывание пациента в стационаре [17]. К сожалению, такого рода сочетания до сих пор популярны в России и других постсоветских странах.

Как мы уже упоминали выше, ОГ, ухудшая кровоток в базальных ганглиях мозга, способна усиливать ЭПС, вызываемую приёмом АП, аналогично тому, как она ухудшает течение БП $[16,17]$. Согласно одной из теорий, именно этим, а вовсе не неблагоприятными фармакокинетическими взаимодействиями (повышением концентрации АП в крови) или повышением суммарного процента оккупации $\mathrm{D}_{2}$-рецепторов нигростриарной системы, объясняется тот давно известный факт, что сочетание мощного, высокопотентного АП (такого, как галоперидол или трифлуоперазин), вызывающего выраженные ЭПС, с низкопотентным седативным АП типа хлорпромазина, левомепромазина или клозапина, вызывающего менее выраженные ЭПС или вообще не обладающего способностью к их 
вызыванию (как клозапин), но зато вызывающего выраженную $\alpha_{1}$-адренергическую блокаду и ОГ, особенно часто приводит к развитию тяжёлых ЭПС [17].

Проявления ОГ на фоне приёма АП могут быть атипичными. Поэтому они легко могут быть не замечены или пропущены клиницистом. Так, в частности, показано, что ОГ на фоне приёма АП может проявляться «отсроченными» обмороками, возникающими не при вставании или ходьбе, а через некоторое время после, причём именно тогда, когда пациент сидит или полулежит в кресле, а не стоит или ходит [64].

Одной из причин этого является то, что мышечная активность, сокращение мышц нижних конечностей, приводит к «выдавливанию» крови из них, к увеличению венозного возврата и облегчению работы сердца. Это может маскировать ортостатическое снижение артериального давления, пока пациент стоит или ходит. В то же время выделение работающими мышцами калия и таких продуктов обмена, как молочная кислота, углекислота, приводит к расширению сосудов для обеспечения адекватного их кровоснабжения. А это приводит к тому, что ортостатические обмороки и коллаптоидные состояния (и «вообще», и на фоне приёма АП) особенно часто случаются не во время, а именно после ходьбы или другой физической нагрузки, во время, казалось бы, спокойного сидения [64].

Между тем, вызываемая АП акатизия обычно сопровождается повышением двигательной активности и напряжением мышц именно нижних конечностей, например, постоянным скрещиванием и раскрещиванием ног или «ходьбой на месте» [65]. А ведь именно эти движения и рекомендуются в качестве мер профилактики ОГ.

Таким образом, акатизия и вызываемая ею моторная гиперактивность и напряжение мышц нижних конечностей может довольно долгое время маскировать проявления ОГ. При этом ОГ может внезапно возникнуть у пациента, казалось бы, ранее хорошо переносившего АП без снижения артериального давления, именно после дачи того или иного корректора, купирования акатизии и достижения моторного успокоения [64].

Важное значение в механизмах развития ОГ на фоне приёма АП имеет также вызываемая ими гиперпролактинемия. Достаточно давно известно, что незначительное повышение концентрации пролактина оказывает вазопрессорное действие. Усиление выделения пролактина при стрессе, физической нагрузке, боли является одним из факторов повышения артериального давления при этих состояниях, хотя и не столь существенным, как повышение активности симпатоадреналовой части вегетативной нерв- 
ной системы и оси ГГН. В то же время известно, что очень высокие концентрации пролактина в крови оказывают, напротив, сосудорасширяющее и гипотензивное действие [66].

Описан, в частности, случай, в котором ОГ была единственным манифестным симптомом вызванной длительным приёмом АП пролактиномы гипофиза (уровень пролактина в этом случае составлял около 1000 нг/мл). При этом все остальные функции гипофиза (тиреотропная, кортикотропная, соматотропная) у данного пациента при тщательном эндокринологическом обследовании оказались интактными. Никакого иного объяснения, кроме прямого гипотензивного действия высоких концентраций пролактина, этому феномену авторы предложить не смогли [66].

Пролактин также оказывает дозозависимое влияние на реабсорбцию воды и натрия почками, характеризующееся колоколообразной кривой. При сравнительно небольшом повышении концентрации пролактина в крови может наблюдаться тенденция к задержке воды и поваренной соли и отёкам. В то же время при значительном повышении уровня пролактина в крови может наблюдаться, напротив, натрийуретическое и гидроуретическое действие и снижение ОЦК. Это, безусловно, также может способствовать развитию ОГ [67].

Кроме того, АП способны также вызывать электролитные нарушения (гипонатриемию, гипокалиемию, гипокальциемию, гипомагнеземию, в основном за счёт повышения секреции вазопрессина и эффекта разведения). Это тоже может предрасполагать к возникновению ОГ на фоне их приёма [62].

\section{Антидепрессанты}

Мы уже упоминали о том, что депрессивные состояния часто сопровождаются ОГ и наоборот. Известно давнее наблюдение о том, что хроническая ОГ часто бывает коморбидна не просто с депрессивными состояниями, а именно с так называемым «норадренергическим», или меланхолическим, подтипом эндогенных депрессий, который связывают с дефицитом норадренергической импульсации в ЦНС [68].

С дефицитом норадреналина в ЦНС связывают, в частности, такие симптомы депрессии, как снижение энергии, активности, нарушение концентрации внимания, психомоторная заторможенность [69].

Более частое проявление ОГ именно при меланхолическом подтипе депрессии, соответственно, приписывают норадренергическому дефициту «на периферии» [68]. 
Трициклические антидепрессанты

Многие ТЦА обладают выраженным $\alpha_{1}$-адреноблокирующим действием. Это обуславливает выраженную гипотензивную активность ТЦА, их способность вызывать рефлекторную тахикардию, а также ОГ и/или ОТ [70].

В частности, в одном исследовании показано, что у 75\% из 150 пациентов в возрасте от 18 до 70 лет, получавших для лечения депрессии кломипрамин, в процессе лечения возникало клинически значимое снижение артериального давления при переходе в стоячее положение $(\mathrm{P}=0,0037)$, в то время как у пациентов с депрессией, получавших обратимый ингибитор МАО-А моклобемид, частота этого осложнения терапии не превышала частоты этого осложнения при приёме плацебо (15,3\% из 150 пациентов, $\mathrm{P}=0,0017)[71]$.

Опять-таки, немалую роль в повышенном риске развития ОГ при приёме ТЦА, наряду с их $\alpha_{1}$-адреноблокирующим действием, играет также их выраженная М-холиноблокирующая и $\mathrm{H}_{1}$-гистаминоблокирующая активность, которая приводит к срыву ауторегуляции мозгового кровотока, к нарушению реакции мозговых сосудов на локальное выделение таких сосудорасширяющих веществ, как ацетилхолин и гистамин [62].

\section{Селективные ингибиторы}

обратного захвата серотонина и норадреналина

Селективные ингибиторы обратного захвата серотонина и норадреналина (СИОЗСиН), к которым относят такие препараты, как венлафаксин и его активный метаболит десвенлафаксин, дулоксетин, милнаципран (рацемический препарат) и левомилнаципран (содержащий только левовращающий изомер милнаципрана), в отличие от ТЦА, не обладают значимой $\alpha_{1}$-адреноблокирующей, М-холиноблокирующей или $\mathrm{H}_{1}$-гистаминоблокирующей активностью. За это, собственно, они и названы «селективными» [72].

По данным некоторых авторов, при применении венлафаксина частота развития ОГ не отличается от частоты развития ОГ при применении плацебо [73]. Напротив, при применении венлафаксина в дозах 225 мг/сут и выше отмечается статистически значимая тенденция к повышению артериального давления, и иногда развитие ятрогенной ГБ [73].

Согласно же другим данным, АД группы СИОЗСиН бывают виновниками развития ОГ хотя и значительно реже, чем ТЦА или необратимые ИМАО, но гораздо чаще, чем АД группы селективных ингибиторов обратного захвата серотонина (СИОЗС), и чаще, чем плацебо [70]. 
Предполагаемый механизм этого эффекта неясен. Считается, что в основе этого явления могут лежать такие механизмы, как, например, даунрегуляция чувствительности периферических $\alpha_{1}$-адренорецепторов на фоне блокады О3 норадреналина и повышения его базальной концентрации в крови, или же компенсаторное ускорение периферического катаболизма норадреналина, или изменение соотношения «адреналин/норадреналин» в периферической крови [70].

В литературе описаны отдельные случаи развития тяжёлой ОГ, вплоть до обмороков и коллаптоидных состояний, при приёме венлафаксина. В одном случае это явление наблюдалось при приеме 225 мг/сут венлафаксина у пожилой женщины (65 лет), до этого в 60-летнем возрасте совершенно нормально переносившей более высокую дозу венлафаксина (300 мг/сут) [74].

В другой серии из шести случаев ОГ, иногда тяжёлая, наблюдалась у молодых пациентов (возраст от 19 до 45 лет) при приёме доз венлафаксина от 150 до 375 мг/сут [75]. Авторы последнего сообщения провели поиск по данным EMBASE. Согласно их анализу данных литературы, в выборке из 1003 пациентов, получавших венлафаксин, ОГ наблюдалась в 1\% случаев, в то время как у других 600 пациентов, получавших плацебо, частота ОГ равнялась строгому нулю (ни одного зарегистрированного случая) [75].

В другой найденной этими же авторами выборке данных, у 10 из 13 пациентов, получавших венлафаксин, наблюдалось клинически значимое снижение артериального давления при переходе из лежачего положения в стоячее. Авторы делают вывод, что, хотя применение СИОЗСиН обычно не ассоциируется с ОГ, тем не менее учитывать такую возможность необходимо. В связи с этим они пишут, что титрация доз венлафаксина должна быть осторожной и постепенной, а пациентов следует инструктировать об опасности резкого вставания с кровати, о необходимости увеличения потребления воды, и регулярно контролировать артериальное давление [75].

В другом исследовании отмечается, что у пациентов с ПР, с их особой чувствительностью к любым изменениям внутреннего телесного состояния, выраженной неустойчивостью сосудистого тонуса (с тем, что на просторах экс-СССР нередко называют «вегето-сосудистой дистонией»), и более сильной зависимостью поддержания нормального артериального давления от уровня катехоламинов в крови, чем в норме, ОГ при применении венлафаксина возникает особенно часто, чаще, чем у пациентов с депрессиями [76].

Возникновение ОГ при лечении венлафаксином документировано не только при депрессивных состояниях и при ПР, но и при лечении мигрени, 
а также при лечении нейропатических болей (в последнем случае, вероятно, возникновение ОГ может потенцироваться одновременным наличием автономной нейропатии, приводящей к дисфункциональной регуляции сосудистого тонуса) [77, 78].

Вместе с тем в обоих случаях авторы подчёркивают, что венлафаксин вызывает ОГ значительно реже, чем ТЦА, бывшие препаратами сравнения в обоих исследованиях $[77,78]$.

При лечении депрессий пожилого и старческого возраста венлафаксин нередко даёт различные сердечно-сосудистые ПЭ. Среди них отмечаются не только артериальная гипертензия, тахикардия и сердечные аритмии, но и ОГ. Общая частота сердечно-сосудистых ПЭ при лечении венлафаксином у пожилых значительно выше, чем у молодых (29\%) [79].

Дулоксетин, судя по всему, имеет лучший профиль кардиоваскулярной безопасности по сравнению с венлафаксином, не только в отношении риска развития артериальной гипертензии, тахикардии или сердечных аритмий, но и в отношении риска ОГ. Так, в одном систематическом мета-обзоре, включающем обзор 42 рандомизированных клинических исследований (РКИ) по дулоксетину, было показано, что частота сердечно-сосудистых ПЭ, включая ОГ, при приёме дулоксетина не отличается от плацебо [80].

В РКИ, проводившемся у пожилых пациентов (возраст старше 65 лет), среднее снижение САД при приёме 60 мг/сут дулоксетина было равно 2,95 мм.рт.ст. Столь небольшое снижение САД, очевидно, не имеет клинического значения. Частота клинически значимой ОГ при приёме дулоксетина была сопоставима с частотой таковой при приёме плацебо (15,6\% при приёме дулоксетина и 20,5\% при приёме плацебо) [81].

Милнаципран и левомилнаципран, по данным исследований, обладают более высокой кардиоваскулярной безопасностью как по сравнению с ТЦА, так и по сравнению с венлафаксином. Показано, что милнаципран гораздо реже вызывает ОГ, чем кломипрамин или венлафаксин [82]. Тем не менее, у единичных пациентов, получавших милнаципран или левомилнаципран, зарегистрированы эпизоды ОГ или, наоборот, повышение артериального давления [83, 84].

Ортостатическая гипотензия как побочный эффект некоторых методов интенсивной биологической терапии в психиатрии

Проблему ОГ в психиатрии нельзя рассматривать однобоко и сводить её только к проявлениям этого ПЭ при приёме ПФТ. Целый ряд применяемых в психиатрии методов немедикаментозной интенсивной биологической терапии (ИБТ) также обладает способностью вызывать или провоцировать 
проявление ОГ. При этом вредные последствия ОГ, вызванной применением того или иного метода ИБТ, для когнитивного и эмоционального функционирования пациента - такие же, как вредные последствия ОГ, вызванной приёмом ПФТ. Поэтому минимизация ОГ при применении ИБТ не менее важна, чем при применении ПФТ.

\section{Ортостатическая гипотензия}

\section{как побочный эффект электросудорожной терапии}

Известно, что ОГ нередко возникает в постсеансовом периоде при проведении ЭСТ $[85,86]$. Согласно одной из гипотез, постсеансовая ОГ, наряду с интрасеансовой гипертензией, является важным фактором риска развития КН при ЭСТ и фактором риска снижения её антидепрессивной эффективности [87].

Показано, что меры по профилактике ОГ после сеанса ЭСТ могут способствовать уменьшению КН при ЭСТ и повышению её эффективности [88].

Патогенетические механизмы, лежащие в основе постсеансовой ОГ при проведении ЭСТ, многообразны и включают в себя, в частности, постсеансовую ваготоническую компенсаторную реакцию на «симпатоадреналовую бурю», происходящую во время собственно сеанса, выделение таких вазоактивных веществ с гипотензивным и сосудорасширяющим действием, как эндогенные опиоиды (эндорфины), инсулин и др., гипотензивное воздействие компонентов премедикации, общей анестезии и препаратов, вводившихся во время сеанса для подавления чрезмерной гипертензивной реакции (в случае её возникновения), наличие у пациента исходной гипертермии, гиповолемии и/или электролитных нарушений и др. [87].

\section{Ортостатическая гипотензия}

\section{как побочный эффект атропинокоматозной терапии}

АКТ также бывает ассоциирована с возникновением постсеансовой ОГ [89]. Патогенез этого явления может быть связан как с воздействием самого атропина, так и с действием его антагониста, ингибитора ацетилхолинэстеразы (ИАХЭ) физостигмина или галантамина при выведении из атропиновой комы, а также с гипотензивным воздействием компонентов премедикации, вводимых для профилактики тошноты и рвоты и уменьшения симпатоадреналовой реакции на АКТ, или с наличием исходной гиповолемии, электролитных нарушений у пациента, с потерями жидкости и солей в результате прессорного диуреза и учащения дыхания [89]. 
Ещё в 1954 году было отмечено, что ОГ иногда возникает даже в ответ на введение малых (обычных в общемедицинской практике и в составе премедикации в анестезиологии) доз атропина [90]. Этот эффект может показаться парадоксальным, так как атропин или экстракт белладонны, а также препараты с его содержанием, например, беллатаминал, давно и достаточно успешно применяются при лечении вазовагальных обмороков, хронической ОГ, ваго-инсулярных вегетативных кризов, и известно, что вазодилатирующее, отрицательное ино- и хронотропное действие ацетилхолина опосредуется именно воздействием на М-холинорецепторы, и что оно снимается или предупреждается введением атропина [91, 92]. Тем не менее, факт остаётся фактом.

Одним из возможных объяснений этого парадоксального факта является то, что атропин, как показали последние данные, способен, несмотря на своё известное свойство учащать сердцебиение и, обычно, повышать артериальное давление, одновременно нарушать ауторегуляцию церебральной гемодинамики в ответ на ортостатический стресс, препятствуя расширению церебральных сосудов в ответ на местное выделение ацетилхолина, и тем самым иногда парадоксально снижать толерантность к ортостатической нагрузке и церебральный гемодинамический резерв [63].

Кроме того, атропин склонен повышать внутричерепное давление. Это приводит к необходимости поддержания более высокого системного артериального давления для обеспечения адекватной перфузии мозга (перфузионное давление представляет собой разницу между системным артериальным давлением и внутричерепным), и, как следствие, может ухудшать толерантность к ортостатической нагрузке [93].

\section{Ортостатическая гипотензия}

\section{как побочный эффект инсулинокоматозной терапии}

Инсулин является вазоактивным веществом, способным вызывать активацию парасимпатической части вегетативной нервной системы (см., в частности, понятие «ваго-инсулярный криз»), и, как следствие, расширение сосудов (прежде всего сосудов органов брюшной полости; на этом основано участие инсулина в организации процессов пищеварения) и снижение системного артериального давления. Именно выделением инсулина, а также других вазоактивных веществ с сосудорасширяющим и гипотензивным действием, таких, как вазоактивный интестинальный пептид, оксид азота (NO), эндорфины, обусловлено 
такое явление, как постпрандиальная гипотензия. Она особенно выражена именно при приёме высокоуглеводной пищи (вызывающей обильную секрецию инсулина) [94].

При проведении ИКТ или форсированной инсулинокоматозной терапии (ФИКТ) это гипотензивное действие инсулина обычно уравновешивается массивным выбросом контррегуляторных гормонов в ответ на гипогликемию, таких, как АКТГ и кортизол, адреналин, тироксин и др., и активацией симпатоадреналовой части вегетативной нервной системы. Это приводит к развитию таких известных проявлений гипогликемии, как потливость, тахикардия, артериальная гипертензия [95].

Однако иногда активация парасимпатической нервной системы преобладает, и в ходе сеанса может наблюдаться брадикардия и гипотензия [95]. После сеанса, как вследствие обильного приёма высокоуглеводной пищи и связанной с этим постпрандиальной гипотензии, так и вследствие компенсаторной парасимпатической реакции на наблюдавшуюся в ходе сеанса симпатоадреналовую реакцию, и вследствие потерь жидкости при обильном потоотделении и учащении дыхания во время сеанса, а также вследствие возможного гипотензивного действия компонентов премедикации, даваемых перед сеансом для уменьшения тошноты, рвоты и вегетативных реакций на ФИКТ, может наблюдаться значительное снижение ортостатической толерантности, и как следствие - предрасположенность к ОГ [95].

Показано, что у пациентов с автономной вегетативной дисфункцией (например, с БП, БА, семейным амилоидозом, СД с автономной нейропатией и др.), может наблюдаться гипотензивная, а не гипертензивная контррегуляторная реакция на вызванную инсулином гипогликемию, и ОГ, связанная с преобладанием сосудорасширяющей $\beta$-адренергической активации над сосудосуживающей $\alpha$-адренергической, а также с прямым парасимпатомиметическим действием инсулина $[96,97]$.

Такой же парадоксальный гипотензивный ответ на инсулин-индуцированную гипогликемию описывается у пациентов с исходно высокой гиперкатехоламинемией и гиперкортизолемией и «насыщением $\alpha$-адренорецепторов». К этой категории, безусловно, относятся и пациенты с многими психическими заболеваниями, прежде всего с депрессивными, тревожными и психотическими состояниями, и с различными СС3 (ГБ, ИБС, ХCH), при которых, как известно, описывается гиперкатехоламинемия и гиперкортизолемия [97].

Это следует иметь в виду при планировании сеансов ИКТ или ФИКТ. 


\section{Ортостатическая гипотензия как побочный эффект депривации сна}

Данные о влиянии депривации сна на толерантность к ортостатической нагрузке и на склонность к возникновению ОГ достаточно противоречивы. Одними авторами указывается, что депривация сна обычно повышает базальное артериальное давление и уменьшает его колебания в ответ на ортостатическую нагрузку и склонность к возникновению ОГ, особенно у пожилых пациентов [98].

Другие авторы не обнаруживают какого-либо влияния депривации сна на переносимость ортостатической нагрузки - ни положительного, ни отрицательного [99]. Третьи же, однако, указывают, что депривация сна всё-таки может вызывать ОГ, причем её симптомы можно спутать с обычной для пост-депривационных состояний сонливостью и усталостью, наблюдаемой до восстановления сил сном (которое, однако, может приводить к исчезновению антидепрессивного эффекта, длившегося в период депривации сна) [100].

Вместе с тем, согласно тем же авторам, хроническое недосыпание или хроническая депривация сна, как спонтанная, так и ятрогенная (проводимая в лечебных целях), также являются фактором риска развития ГБ и других СС3, а также ожирения и метаболических нарушений [100].

В свою очередь, как уже указывалось, СС3, ожирение и нарушения обмена веществ могут сами по себе предрасполагать к развитию ОГ [100].

\section{Ортостатическая гипотензия как побочный эффект гипербарической оксигенации}

Гипербарическая оксигенация (ГБО) - известный метод ИБТ в психиатрии, служащий преодолению резистентности к ПФТ. Исследования показывают, что ГБО вызывает гипербарический диурез (увеличение выделения мочи), повышение осмоляльности плазмы, снижение ОЦК, тахикардию покоя, снижение толерантности к ортостатической нагрузке, и, как следствие, ОГ и ОТ [101, 102].

\section{Ортостатическая гипотензия}

\section{как побочный эффект разгрузочно-диетической терапии}

Разгрузочно-диетическая терапия (РДТ) также является давно и хорошо известным методом ИБТ в психиатрии, способствующим преодолению резистентности к ПФТ. Однако, вызывая дефицит нутриентов, необходимых для поддержания нормального артериального давления, она может 
способствовать или предрасполагать к развитию ОГ. Особенно значителен этот риск при исходном не очень хорошем соматическом состоянии пациента, а также при проведении РДТ в формате «сухого голодания», при котором, помимо нутритивных дефицитов, может также развиваться гиповолемия [44].

\section{Ортостатическая гипотензия как побочный эффект пиротерапии}

Пиротерапия, или лихорадочная терапия, независимо от применяемого агента (будь то сульфозин, пирогенал или физическое нагревание тела, например, в инфракрасной сауне), также ассоциируется с риском возникновения ОГ. Причиной тому являются такие факторы, как обильная потеря жидкости и электролитов при усиленном потоотделении и учащении дыхания, вазоплегия поверхностных сосудов кожи, влияние массивного выделения цитокинов в кровь при введении сульфозина или пирогенала $[44,103,104]$.

\section{Некоторые интересные клинические случаи ортостатической гипотензии в психиатрии}

Ещё в 1972 году Дж. Джефферсон описал 27-летнего пациента с шизофренией, получавшего хлорпромазин (800 мг/сут - 200 мг 4 раза в сутки, что в те времена считалось обычными его дозами) и трифлуоперазин (20 мг/сут - 10 мг 2 раза в сутки). Этот пациент не проявлял каких бы то ни было признаков ОГ или мышечной слабости в процессе акатизивной ходьбы по отделению или при походе в кабинет врача. Однако он рухнул в ортостатический обморок именно в кресле, в спокойном состоянии, в кабинете врача, и именно после рассасывания 2 мг биперидена, снявшего моторные проявления акатизии [64].

Анализируя описанный им случай, Дж. Джефферсон отметил, что ОГ на фоне приёма АП и вызываемая именно ею сонливость, слабость, вялость, апатия и адинамия может быть легко спутана с вызываемой седативным действием АП сонливостью и седацией, или с вызываемой ЭПС двигательной заторможенностью, или с депрессивными или апато-абулическими негативными проявлениями самой болезни. Более того, как он пишет, даже в описываемом им случае, упомянутый 27-летний пациент выглядел вовсе не рухнувшим в обморок, а «спокойно заснувшим». Однако он не реагировал на окрик, щипок, а при измерении артериального давления обнаружились цифры порядка 80/0. После этого было предпри- 
нято экстренное в/в введение $\alpha$-адреномиметиков и глюкокортикоидов, вазопрессина, обильная инфузия кристаллоидов, а хлорпромазин был немедленно отменен (трифлуоперазин оставлен) [64].

Как указывает Дж. Джефферсон, опасность такого рода атипичных проявлений ОГ и трудность их дифференциальной диагностики с сонливостью и седацией или с проявлениями ЭПС на фоне приёма АП часто недооценивается [64].

Он также подчёркивает, что к развитию тяжёлой ОГ в случае описанного пациента привели не только высокая начальная и конечная доза сильного $\alpha_{1}$-адреноблокатора хлорпромазина и её быстрое наращивание в ходе терапии, но также полинейролепсия и наличие выраженных ЭПС (которые, напомним, ассоциируются с возникновением ОГ по механизму, подобному механизму возникновения ОГ при БП) [64].

В другом интересном сообщении описывается тяжёлая, полирезистентная ОГ у 60-летнего пациента с шизофренией, ранее хорошо переносившего высокие дозы АП (200 мг/мес галоперидола деканоата), но с годами развившего позднюю дискинезию (ПД), при попытке перевода его, в связи с развитием ПД, на атипичный АП (ААП) рисперидон и затем, при неудаче, на палиперидон. Следует отметить, что и рисперидон, и особенно палиперидон, обладают не очень сильной $\alpha_{1}$-адреноблокирующей активностью (по сравнению с такими ААП, как клозапин или кветиапин), и относительно редко вызывают ОГ. Кроме того, дозы, применявшиеся у этого пациента, были невысокими (2-3 мг рисперидона, затем 3 мг палиперидона) [105].

Тем не менее, ОГ у этого пациента была настолько тяжёлой, что потребовала применения целого комплекса лечебных мероприятий: компрессионных чулков, физических упражнений, назначения обильного питья воды, таблеток поваренной соли и калия хлорида, затем добавления также 225 мг/сут венлафаксина, затем добавления сверх того 0,2 мг/сут флудрокортизона (кортинеффа, синтетического минералокортикоида), затем добавления также 10 мг три раза в сутки мидодрина (периферического $\alpha_{1}$-адренергического агониста), и в конце концов добавления сверх того 10 мг/сут пролонгированного амфетамина (Adderall XR, ПС с дофаминергическими и норадренергическими свойствами) [105].

Только на этой комбинированной терапии артериальное давление у данного пациента удалось стабилизировать, а ортостатические обмороки - предотвратить. Особый интерес представляет в данном случае то, что психическое состояние этого пациента не удавалось стабилизировать, пока 
не была ликвидирована ОГ. Более того, интересно, что назначение пролонгированного амфетамина в случае этого пациента не только не привело к декомпенсации основного психического заболевания (шизофрении), но даже улучшило его психическое состояние [105].

В этой связи авторы, описавшие вышеупомянутый случай, подчёркивают, что ОГ, как возможная причина резистентности к проводимой ПФТ, часто недооценивается [105].

В собственном опыте одного из авторов данной статьи имеется случай резистентного ПР у 32-летней женщины, в котором панические атаки (не только ортостатические) не удавалось купировать стандартной ПФТ и психотерапией, до того, как к лечению были добавлены последовательно: увеличение потребления воды и электролитов (включая дополнительный приём препаратов $\mathrm{K}, \mathrm{Mg}$ и Са), дозированные физические нагрузки, рекомендация спать с приподнятым головным концом кровати, вставать с кровати медленно и плавно, компрессионные чулки 2-й степени компрессии, 0,1 мг/сут флудрокортизон (кортинефф), венотоник диосмин (детралекс). И только последовательное выполнение пациенткой этих рекомендаций привело к терапевтическому успеху.

\section{ЗАКЛЮЧЕНИЕ}

Как видно из представленных нами данных литературы, ОГ является не просто одним из часто наблюдаемых вредных и нежелательных ПЭ психиатрического лечения, но явлением, которое может повлечь за собой многочисленные нежелательные последствия для самых различных систем и органов пациента, и в том числе - непосредственно для его психики.

Развитие ОГ может быть причиной развития КН, снижения памяти, концентрации внимания, ухудшения настроения и общего самочувствия, усиления депрессивной, тревожной или апато-абулической симптоматики, развития патологической сонливости, вялости и адинамии, причиной усиления ЭПС и др. Кроме того, ОГ может также быть причиной явного или скрытого снижения комплаентности пациента к лечению или даже его полного отказа от лечения, или причиной развития резистентности пациента к проводимой терапии.

В свете этого, активная профилактика и лечение ОГ в психиатрии имеют важное значение не только для повышения общего качества жизни пациентов с психическими заболеваниями, улучшения их отношения к лечению, профилактики тяжёлых осложнений, связанных с ОГ, но и непосредственно для улучшения психического состояния этих пациентов и 
для повышения эффективности ПФТ и биологических методов лечения. Представленные нами в статье клинические примеры, в том числе пример из нашей собственной практики, иллюстрируют этот тезис.

\section{Список литературы}

1. Krassioukov A., Eng J.J., Warburton D.E., Teasell R. A Systematic Review of the Management of Orthostatic Hypotension Following Spinal Cord Injury. Archives of Physical and Medical Rehabilitation, 2009, vol. 90, no. 5, p. 876-885. doi: 10.1016/j.apmr.2009.01.009

2. Healy D. The creation of psychopharmacology. Harvard: Harvard University Press, 2009, 469 p. ISBN 978-0674006195

3. Perlmuter L.C., Sarda G., Casavant V., Mosnaim A.D. A review of the etiology, associated comorbidities, and treatment of orthostatic hypotension. American Journal of Therapeutics, 2013, vol. 20, no.3, pp. 279-291. doi: 10.1097/ MJT.0b013e31828bfb7f

4. Jones P.K., Shaw B.H., Raj S.R. Orthostatic hypotension: managing a difficult problem. Expert Review of Cardiovascular Therapy, 2015, vol. 13, no. 11, pp. 1263-1276. doi: 10.1586/14779072.2015.1095090

5. Arbogast S.D., Alshekhlee A., Hussain Z., McNeeley K., Chelimsky T.C. Hypotension unawareness in profound orthostatic hypotension. American Journal of Medicine, 2009, vol. 122, no. 6, pp. 574-580. doi: 10.1016/j.amjmed.2008.10.040

6. Robertson D., Kincaid D.W., Haile V., Robertson R.M. The head and neck discomfort of autonomic failure: an unrecognized aetiology of headache. Clinical Autonomic Research, 1994, vol. 4, no. 3, pp. 99-103. doi: 10.1007/BF01845772

7. Khurana R.K. Coat-hanger ache in orthostatic hypotension. Cephalalgia, 2012, vol. 32, no. 10, pp. 731-737. doi: 10.1177/0333102412449932

8. Sullivan S.D., Hanauer J., Rowe P.C., Barron D.F., Darbari A., Oliva-Hemker M. Gastrointestinal symptoms associated with orthostatic intolerance. Journal of Pediatric Gastroenterology and Nutrition, 2005, vol. 40, no. 4, pp. 425-428. doi: 10.1097/01.MPG.0000157914.40088.31

9. Deb A., Morgenshtern K., Culbertson C.J., Wang L.B., Hohler A.D. A survey-based analysis of symptoms in patients with postural orthostatic tachycardia syndrome. Baylor University Medical Center Proceedings, 2015, vol. 28, no. 2, pp. 157-159. doi: 10.1080/08998280.2015.11929217

10. Rye D.B. Sleepiness and Unintended Sleep in Parkinson's Disease. Current Treatment Options in Neurology, 2003, vol. 5, no. 3, pp. 231-239. doi: 10.1007/ s11940-003-0014-Z 
11. Robinson M.J. Are newer antidepressants really «better tolerated»? The Canadian Journal of Psychiatry, 2001, vol. 46, no.3, pp. 286-287. doi: 10.1177/070674370104600314

12. Frewen J., Savva G.M., Boyle G., Finucane C., Kenny R.A. Cognitive performance in orthostatic hypotension: findings from a nationally representative sample. Journal of the American Geriatrics Society, 2014, vol. 62, no.1, pp. 117-122. doi: 10.1111/jgs. 12592

13. Reggiani P., Magrini F., Mondadori C., Branzi G., Zanchetti A. Marked blood pressure fluctuations during narcoleptic attacks alternating with abnormal wakefulness: effects of treatment with clonidine. European Heart Journal, 1989, vol. 10, no. 1, pp. 2-7. doi: 10.1093/oxfordjournals.eurheartj.a059376

14. Casavant V., Chae C., Sherwani A., Perlmutter L.C. Subclinical orthostatic pulse pressure confirms mothers' ratings of ADHD in preschoolers. Psychophysiology, 2012, vol. 49, no. 5, pp. 708-712. doi: 10.1111/j.1469-8986.2012.01351.x

15. Kotagal V., Lineback C., Bohnen N.I., Albin R.L. Orthostatic hypotension predicts motor decline in early Parkinson disease. Parkinsonism and Related Disorders, 2016, vol. 32, pp. 127-129. doi: 10.1016/j.parkreldis.2016.09.011

16. Kojima T., Tada K. Neuroleptics and antidepressants. No To Shinkei, 1992, vol. 44, no. 12, pp. 1077-1082.

17. Schwartz J.T., Brotman A.W. A clinical guide to antipsychotic drugs. Drugs, 1992, vol. 44, no. 6, pp. 981-992. doi: 10.2165/00003495-199244060-00007

18. Cavanaugh R.M. Jr. Evaluating adolescents with fatigue: ever get tired of it? Pediatrics in Review, 2002, vol. 23, no. 10, pp. 337-348. doi: 10.1542/pir.23-10-337

19. Czajkowska J., Ozhog S., Smith E., Perlmutter L.C. Cognition and hopelessness in association with subsyndromal orthostatic hypotension. The Journals of Gerontology: Series A, 2010, vol. 65, no. 8, pp. 873-879. doi: 10.1093/gerona/glq068

20. Regan C.O., Kearney P.M., Cronin H., Savva G.M., Lawlor B.A., Kenny R. Oscillometric measure of blood pressure detects association between orthostatic hypotension and depression in population based study of older adults. $B M C$ Psychiatry, 2013, vol. 13, p. 266. doi: 10.1186/1471-244X-13-266

21. Modugno N., Lena F., Di Biasio F., Cerrone G., Ruggieri S., Fornai F. A clinical overview of non-motor symptoms in Parkinson's Disease. Archives Italiennes de Biologie, 2013, vol. 151, no. 4, pp. 148-168.

22. Ricci F., De Caterina R., Fedorowski A. Orthostatic Hypotension: Epidemiology, Prognosis, and Treatment. Journal of American College of Cardiology, 2015, vol. 66, no. 7, pp. 848-860. doi: 10.1016/j.jacc.2015.06.1084

23. Gupta V., Lipsitz L.A. Orthostatic hypotension in the elderly: diagnosis and treatment. American Journal of Medicine, 2007, vol. 120, no. 10, pp. 841-847. doi: 10.1016/j.amjmed.2007.02.023 
24. Chou R.H., Liu C.J., Chao T.F., Chen S.J., Tuan T.C., Chen T.J., Chen S.A. Association between orthostatic hypotension, mortality, and cardiovascular disease in Asians. International Journal of Cardiology, 2015, vol. 195, pp. 40-44. doi: 10.1016/j.ijcard.2015.05.060

25. Edgell H., Robertson A.D., Hughson R.L. Hemodynamics and brain blood flow during posture change in younger women and postmenopausal women compared with age-matched men. Journal of Applied Physiology, 2012, vol. 112, no. 9, pp. 1482-1493. doi: 10.1152/japplphysiol.01204.2011

26. Van Dijk N., Wieling W. Fainting, emancipation and the 'weak and sensitive' sex. The Journal of Physiology, 2009, vol. 587, no. 13, pp. 3063-3064. doi: 10.1113/jphysiol.2009.174672

27. Canada S.A., Hofkamp M., Gall E.P., Perlmuter L.C. Estrogen replacement therapy, subsyndromal depression, and orthostatic blood pressure regulation. Behavioral Medicine, 2003, vol. 29, no. 3, pp. 101-106. doi: 10.1080/08964280309596062

28. Lide B., Haeri S. A Case Report and Review of Postural Orthostatic Tachycardia Syndrome in Pregnancy. American Journal of Perinatology Reports, 2015, vol. 5, no. 1, pp. e33-e36. doi: 10.1055/s-0034-1544106

29. Barnes T.R., Katona C.L. Susceptibility to drug-induced hypotension in post-partum psychosis. International Clinical Psychopharmacology, 1986, vol. 1, no. 1, pp. 74-76. doi: 10.1097/00004850-198601000-00009

30. Strogatz D.S., Keenan N.L., Barnett E.M., Wagner E.H. Correlates of postural hypotension in a community sample of elderly blacks and whites. Journal of the American Geriatrics Society, 1991, vol. 39, no. 6, pp. 562-566. doi: 10.1111/ j.1532-5415.1991.tb03593.x

31. Shvartz E., Wyndham C.H., Strydom N.B. Orthostatic responses in Caucasians and Bantu. Aviation, Space and Environmental Medicine, 1975, vol. 46, no. 11, pp. 1343-1348.

32. Clark R., Tyroler H.A., Heiss G. Orthostatic blood pressure responses as a function of ethnicity and socioeconomic status: the ARIC study. Annals of the New York Academy of Sciences, 1999, vol.896, pp. 316-317. doi: 10.1111/j.17496632.1999.tb08127.x

33. Kuruvilla A., Jacob K.S. Poverty, social stress and mental health. The Indian Journal of Medical Research, 2007, vol. 126, no. 4, pp. 273-278.

34. Ludwig D.A., Convertino V.A. Predicting orthostatic intolerance: physics or physiology? Aviation, Space and Environmental Medicine, 1994, vol. 65, no. 5, pp. 404-411.

35. Lee J.F., Harrison M.L., Christmas K.M., Kim K., Hurr C., Brothers R.M. Elevated resting heart rate and reduced orthostatic tolerance in obese humans. 
Clinical Autonomic Research, 2014, vol. 24, no. 1, pp. 39-46. doi: 10.1007/ s10286-013-0222-x

36. Maser R.E., Lenhard M.J. An overview of the effect of weight loss on cardiovascular autonomic function. Current Diabetes Reviews, 2007, vol. 3, no. 3, pp. 204-211. doi: 10.2174/157339907781368931

37. Narkiewicz K., Cooley R.L., Somers V.K. Alcohol potentiates orthostatic hypotension: implications for alcohol-related syncope. Circulation: Journal of the American Heart Association, 2000, vol. 101, no. 4, pp. 398-402. doi: 10.1161/01.cir.101.4.398

38. Carter J.R., Stream S.F., Durocher J.J., Larson R.A. Influence of acute alcohol ingestion on sympathetic neural responses to orthostatic stress in humans. American Journal of Physiology-Endocrinology and Metabolism, 2011, vol. 300, no. 5, pp. E771-E778. doi: 10.1152/ajpendo.00674.2010

39. Gaxatte C., Faraj E., Lathuillerie O., Salleron J., Deramecourt V., Pardessus V., Destailleur M.H., Boulanger E., Puisieux F. Alcohol and psychotropic drugs: risk factors for orthostatic hypotension in elderly fallers. Journal of Human Hypertension, 2017, vol. 31, no. 4, pp. 299-304. doi: 10.1038/jhh.2013.82

40. Merritt J.C., Cook C.E., Davis K.H. Orthostatic hypotension after delta 9-tetrahydrocannabinol marihuana inhalation. Ophthalmic Research, 1982, vol. 14, no. 2, pp. 124-128. doi: 10.1159/000265183

41. Benowitz N.L., Jones R.T. Cardiovascular and metabolic considerations in prolonged cannabinoid administration in man. The Journal of Clinical Pharmacology, 1981, vol. 21, no. S1, pp. 214S-223S. doi: 10.1002/j.1552-4604.1981. tb02598.x

42. LaWall J.S. Treatment of psychotropic-caused orthostatic hypotension. Psychosomatics, 1980, vol. 21, no. 8, pp. 693-694. doi: 10.1016/S0033-3182(80)73636-8

43. Knight J., Nigam Y., Jones A. Effects of bedrest 1: cardiovascular, respiratory and haematological systems. Nursing Times, 2009, vol. 105, no. 21, pp. 16-20.

44. Быков Ю.В., Беккер Р.А., Резников М.К. Депрессии и резистентность. М.:РИОР, 2013. 374 c. ISBN 978-5-369-01096-9

45. Llach F., Weidmann P., Reinhart R., Maxwell M.H., Coburn J.W., Massry S.G. Effect of acute and long-standing hypocalcemia on blood pressure and plasma renin activity in man. The Journal of Clinical Endocrinology and Metabolism, 1974, vol. 38, no.5, pp. 841-847. doi: 10.1210/jcem-38-5-841

46. Antiel R.M., Caudill J.S., Burkhardt B.E., Brands C.K, Fischer P.R. Iron insufficiency and hypovitaminosis $\mathrm{D}$ in adolescents with chronic fatigue and orthostatic intolerance. Southern Medical Journal, 2011, vol. 104, no. 8, pp. 609-611. doi: 10.1097/SMJ.0b013e3182246809 
47. Lukkarinen H., Peltola V. Influenza A induced acute autonomic neuropathy in an adolescent. Pediatric Neurology, 2010, vol. 43, no. 6, pp. 425-426. doi: 10.1016/j.pediatrneurol.2010.06.011

48. Summers Q., Harris A. Autonomic neuropathy after rubella infection. Medical Journal of Australia, 1987, vol. 147, no. 7, pp. 353-355. 10.5694/j.13265377.1987.tb133521.x

49. Clegg A., Daverede L., Wong W., Loney E., Young J. Recurrent syncope and chronic ear pain. BMJ Case Reports, 2010, pii: bcr0620103109. doi: 10.1136/ bcr.06.2010.3109

50. Itoh Y., Oishi T., Ohnishi A. Acute cerebellar ataxia with sympathotonic orthostatic hypotension following Epstein-Barr virus infection--a case report. Rinsho Shinkeigaku, 1993, vol. 33, no. 5, pp. 503-506.

51. Prange H. Possible involvement of the autonomic nervous system in herpes zoster. Der Internist, 1996, vol. 37, no. 11, pp. 1168-1169.

52. Tamura N., Shimazu K., Yamamoto T., Itokawa K., Hamaguchi K. A case of sympathotonic orthostatic hypotension following herpes simplex encephalitis. Rinsho Shinkeigaku, 1996, vol. 36, no. 10, pp. 1161-1165.

53. Kleiter I., Steinbrecher A., Flügel D., Bogdahn U., Schulte-Mattler W. Autonomic involvement in tick-borne encephalitis (TBE): report of five cases. European Journal of Medical Research, 2006, vol. 11, no. 6, pp. 261-265.

54. Johnson K., Sargent L.A., Galizio C., Ubogu E.E. Interferon-alpha-2b/ribavirin-induced vestibulocochlear toxicity with dysautonomia in a chronic hepatitis C patient. European Journal of Gastroenterology and Hepatology, 2008, vol. 20, no. 11, pp. 1110-1114. doi: 10.1097/MEG.0b013e3282f8e583

55. Nakao K., Namekawa M., Kondo S., Ono S., Nakano I. Subacute autonomic and sensory neuropathy closely related to cytomegalovirus infection preceded by frequent syncopal attacks. Rinsho Shinkeigaku, 2016, vol. 56, no. 8, pp. 555559. doi: 10.5692/clinicalneurol.cn-000863

56. DeYoung P., Martyn J., Wass H., Harth L., Crichton E., Reynolds C. Toxic shock syndrome associated with a contraceptive diaphragm. Canadian Medical Association Journal, 1982, vol. 127, no. 7, pp. 611-612.

57. Cohen J.A., Miller L., Polish L. Orthostatic hypotension in human immunodeficiency virus infection may be the result of generalized autonomic nervous system dysfunction. Journal of Acquired Immune Deficiency Syndromes, 1991, vol. 4 , no. 1 , pp. 31-33.

58. Grange C., Augey L., Durieu I., Vital Durand D., Levrat R. Orthostatic hypotension revealing HIV infection. Presse Medicale, 1993, vol. 22, no. 34, p. 1748.

59. Dore M.X., de La Blanchardière A., Lesprit P., David F., Beressi J.P., Fiet J., Sicard D., Decazes J.M. Peripheral adrenal insufficiency in AIDS. La Revue 
de Médecine Interne, 1998, vol. 19, no. 1, pp. 23-28. doi: 10.1016/S02488663(97)83695-8

60. Pathak A., Lapeyre-Mestre M., Montastruc J.L., Senard J.M. Heat-related morbidity in patients with orthostatic hypotension and primary autonomic failure. Movement Disorders, 2005, vol. 20, no. 9, pp. 1213-1219. doi: 10.1002/mds.20571

61. McCarthy P., Snyder J.C. Orthostatic hypotension: a potential side effect of psychiatric medications. Journal of Psychosocial Nursing and Mental Health Services, 1992, vol. 30, no. 8, pp. 3-5. doi: 10.3928/0279-3695-19920801-05

62. Stahl S.M. Stahl's Essential Psychopharmacology. Neuroscientific Basis and Practical Application. Cambridge:Cambridge University Press, 2013, 628 p. ISBN 978-1107025981

63. Choi W.J., Lee K., Kim Y.K, Song K.J., Jeong S.M., Hwang G.S. Vagolytic atropine attenuates cerebral vasodilation response during acute orthostatic hypotension. Korean Journal of Anesthesiology, 2015, vol. 68, no. 6, pp. 594-602. doi: 10.4097/kjae.2015.68.6.594

64. Jefferson J.W. Atypical manifestations of postural hypotension. Archives of General Psychiatry, 1972, vol. 27, no. 2, pp. 250-251. doi: 10.1001/archpsyc. 1972.01750260092014

65. Беккер Р.А., Быков Ю.В. Акатизия: клинический анализ патологии с рекомендациями и обзором литературы. Доступно по веб-адресу: https:// con-med.ru/partner_article/all/akatiziya-klinicheskiy-analiz-patologii-srekomendatsiyami-i-obzorom-literatury/ Доступ проверен: 10.09.2019.

66. Ducloux G., Manouvrier J., Wemeau J.L., Christiaens J.L., Barbry M., Sarkis E.H. Orthostatic hypotension due to prolactin-secreting pituitary adenoma. American Heart Journal, 1984, vol. 107, no. 1, pp. 187-188. doi: 10.1016/00028703(84)90164-9

67. Ibarra F., Crambert S., Eklöf A.C., Lundquist A., Hansell P., Holtbäck U. Prolactin, a natriuretic hormone, interacting with the renal dopamine system. Kidney International, 2005, vol. 68, no. 4, pp. 1700-1707. doi: 10.1111/j.15231755.2005.00586.x

68. Brakha S. Orthostatic hypertension, a constant symptom of endogenous depressive attacks due to cerebral noradrenergic hypofunction. Revue Neurologique, 1972, vol. 127, no. 2, pp. 323-325.

69. Мазо Г.Э., Незнанов Н.Г. Терапевтически резистентные депрессии. СПб.:Береста, 2012. 448 с. ISBN 978-5-905225-48-2

70. Darowski A., Chambers S.A., Chambers D.J. Antidepressants and falls in the elderly. Drugs and Aging, 2009, vol. 26, no. 5, pp. 381-394. doi: 10.2165/00002512200926050-00002 
71. Stage K.B. Orthostatic side effects of clomipramine and moclobemide during treatment for depression. Nordic Journal of Psychiatry, 2005, vol. 59, no. 4, pp. 298-301. doi: 10.1080/08039480500213725

72. Feighner J.P. The role of venlafaxine in rational antidepressant therapy. The Journal of Clinical Psychiatry, 1994, vol. 55, no. Suppl. A, pp. 62-68.

73. Feighner J.P. Cardiovascular safety in depressed patients: focus on venlafaxine. The Journal of Clinical Psychiatry, 1995, vol. 56, no. 12, pp. 574-579.

74. Chikkaramanjegowda V., de Leon J. Venlafaxine-induced orthostatic hypotension in a geriatric patient. Case Reports in Psychiatry, 2013, article id: 761567. doi: 10.1155/2013/761567

75. Duggal H.S., Jagadheesan K., Nizamie HS. Venlafaxine-induced orthostatic hypotension. Indian Journal of Psychiatry, 2001, vol. 43, no. 4, pp. 371-373.

76. Gorman J.M. The use of newer antidepressants for panic disorder. The Journal of Clinical Psychiatry, 1997, vol. 58, no. Suppl 14, pp. 54-58.

77. Bulut S., Berilgen M.S., Baran A., Tekatas A., Atmaca M., Mungen B. Venlafaxine versus amitriptyline in the prophylactic treatment of migraine: randomized, double-blind, crossover study. Clinical Neurology and Neurosurgery, 2004, vol. 107, no. 1, pp. 44-48. doi: 10.1016/j.clineuro.2004.03.004

78. Haanpää M.L., Gourlay G.K., Kent J.L., Miaskowski C., Raja S.N., Schmader K.E., Wells C.D. Treatment considerations for patients with neuropathic pain and other medical comorbidities. Mayo Clinic Proceedings, 2010, vol. 85, no. Suppl 3, pp. S15-S25. doi: 10.4065/mcp.2009.0645

79. Johnson E.M., Whyte E., Mulsant B.H., Pollock B.G., Weber E., Begley A.E., Reynolds C.F. Cardiovascular changes associated with venlafaxine in the treatment of late-life depression. The American Journal of Geriatric Psychiatry, 2006, vol. 14, no. 9, pp. 796-802. doi: 10.1097/01.JGP.0000204328.50105.b3

80. Wernicke J., Lledó A., Raskin J., Kajdasz D.K., Wang F. An evaluation of the cardiovascular safety profile of duloxetine: findings from 42 placebo-controlled studies. Drug Safety, 2007, vol. 30, no. 5, pp. 437-455. doi: 10.2165/00002018200730050-00007

81. Raskin J., Wiltse C.G., Dinkel J.J., Walker D.J., Desaiah D., Katona C. Safety and tolerability of duloxetine at $60 \mathrm{mg}$ once daily in elderly patients with major depressive disorder. Journal of Clinical Psychopharmacology, 2008, vol. 28, no. 1, pp. 32-38. doi: 10.1097/jcp.0b013e318160738e

82. Leinonen E., Lepola U., Koponen H., Mehtonen O.P., Rimon R. Long-term efficacy and safety of milnacipran compared to clomipramine in patients with major depression. Acta Psychiatrica Scandinavica, 1997, vol. 96, no. 6, pp. 497-504. doi: 10.1111/j.1600-0447.1997.tb09953.x 
83. Mago R., Mahajan R., Thase M.E. Levomilnacipran: a newly approved drug for treatment of major depressive disorder. Expert Review of Clinical Pharmacology, 2014, vol. 7, no. 2, pp. 137-145. doi: 10.1586/17512433.2014.889563

84. Bruno A., Morabito P., Spina E., Muscatello M.R. The Role of Levomilnacipran in the Management of Major Depressive Disorder: A Comprehensive Review. Current Neuropharmacology, 2016, vol. 14, no. 2, pp. 191-199. doi: 10.2174/1 570159X14666151117122458

85. Rasmussen K.G., Leise A.D., Stevens S.R. Orthostatic hemodynamic changes after electroconvulsive therapy treatments. The Journal of ECT, 2008, vol. 24, no. 2, pp. 134-136. doi: 10.1097/YCT.0b013e318156dffb

86. Быков Ю.В. Электросудорожная терапия в практике анестезиолога. М.:РИOP, 2013. 222 c. ISBN 978-5-369-01140-9

87. Быков Ю.В., Беккер Р.А. Минимизация когнитивных нарушений при электросудорожной терапии: реалии и перспективы (Обзор литературы с комментариями и рекомендациями) (І часть: Теоретическая //В мире научных открытий. 2016. Т. 10. №. 82. С. 54-92. doi: 10.12731/wsd-2016-10-54-92

88. Быков Ю.В., Беккер Р.А. Минимизация когнитивных нарушений при электросудорожной терапии: реалии и перспективы (Обзор литературы с комментариями и рекомендациями) (ІІ часть: Практическая)//В мире научных открытий. 2016. Т. 12. №. 84. С. 200-272. doi: 10.12731/wsd-2016-12-200-272

89. Быков Ю.В., Нельсон А.И. Атропинокоматозная терапия: взгляд на проблему (Обзор литературы). Доступно по веб-адресу: https://psychoreanimatology. org/modules/articles/article.php?id=61 Доступ проверен: 10.09.2019

90. Kalser M.H., Frye C.W., Gordon A.S. Postural hypotension induced by atropine sulfate. Circulation, 1954, vol. 10, no. 3, pp. 413-422. doi: 10.1161/01.cir.10.3.413

91. Thulesius O. Therapy of arterial hypotension. Die Medizinische Welt, 1975, vol. 26, no. 13, pp. 588-591.

92. Weise F., Baltrusch K., Heydenreich F. Effect of low-dose atropine on heart rate fluctuations during orthostatic load: a spectral analysis. Journal of the Autonomic Nervous System, 1989, vol. 26, no.3, pp. 223-230. 10.1016/01651838(89)90171-9

93. Smith M., Ray C.T. Cardiac arrhythmias, increased intracranial pressure, and the autonomic nervous system. Chest, 1972, vol. 61, no. 2, pp. 125-133. doi: 10.1378/chest.61.2.125

94. Saito Y., Ishikawa J., Harada K. Postprandial and Orthostatic Hypotension Treated by Sitagliptin in a Patient with Dementia with Lewy Bodies. The American Journal of Case Reports, 2016, vol. 17, pp. 887-893. doi: 10.12659/ AJCR.900620 
95. Нельсон А.И. Краткое пособие для врачей по применению метода форсированной инсулинокоматозной терапии (ФИКТ). Доступно по веб-адреcy: https://psychoreanimatology.org/modules/articles/article.php?id=27 Доступ проверен: 10.09.2019

96. Brown R.T., Polinsky R.J., Lee G.K., Deeter J.A. Insulin-induced hypotension and neurogenic orthostatic hypotension. Neurology, 1986, vol. 36, no. 10, pp. 1402-1406. doi: 10.1212/wnl.36.10.1402

97. Ishikawa Y., Shimatsu A., Imura H., Tatsuoka Y., Fujitake J. Effects of insulin-induced hypoglycemia on catecholamine secretion and blood pressure in neurological disorders affecting autonomic nervous system. Rinsho Shinkeigaku, 1992, vol. 32, no. 3, pp. 281-286.

98. Robillard R., Lanfranchi P.A., Prince F., Filipini D., Carrier J. Sleep deprivation increases blood pressure in healthy normotensive elderly and attenuates the blood pressure response to orthostatic challenge. Sleep, 2011, vol. 34, no. 3, pp. 335-339. doi: 10.1093/sleep/34.3.335

99. Grenon S.M., Hurwitz S., Sheynberg N., Xiao X., Judson B., Ramsdell C.D., Kim C., Cohen R.J., Williams G.H. Sleep restriction does not affect orthostatic tolerance in the simulated microgravity environment. Journal of Applied Physiology, 2004, vol. 97, no. 5, pp. 1660-1666. doi: 10.1152/japplphysiol.00328.2004

100. Calvin A.D., Caples S.M. Getting to the heart of sleep deprivation. Sleep, 2011, vol. 34, no. 3, pp. 251-252. doi: 10.1093/sleep/34.3.251

101. Lin Y.C., Shiraki K., Takeuchi H., Mohri M. Cardiovascular deconditioning occurs during a 7-day saturation dive at 31 ATA. Aviation, Space, and Environmental Medicine, 1995, vol. 66, no. 7, pp. 656-660.

102. Claybaugh J.R., Lin Y.C., Schafstall H.G., Bennett P.B. Cardiovascular and endocrine responses to 90 degree tilt during a 35-day saturation dive to 46 and 37 ATA. Aviation, Space, and Environmental Medicine, 2007, vol. 78, no. 11, pp. 1042-1049.

103. Беккер Р.А., Быков Ю.В. Сульфозин-продукт психиатрической школы СССР: терапевтический агент или средство карательной психиатрии? //В мире научных открытий. 2017. Т. 9. №. 2. С. 214-242. doi: 10.12731/ wsd-2017-2-214-242

104. Быков Ю.В., Беккер Р.А. Пирогенал в психиатрии, неврологии и наркологии: история, механизмы лечебного воздействия и результаты //В мире научных открытий. 2017. Т. 9. №. 4-2. С. 101-136. doi: 10.12731/wsd-2017-4-2-101-136

105. Gambhir S., Sandersfeld N., D’Mello D. A Case of Severe, Refractory Antipsychotic-Induced Orthostatic Hypotension. Medical Student Research Journal, 2014. doi: $10.3402 / \mathrm{msrj} . \mathrm{v} 3 \mathrm{i} 0.201337$ 


\section{References}

1. Krassioukov A., Eng J.J., Warburton D.E., Teasell R. A Systematic Review of the Management of Orthostatic Hypotension Following Spinal Cord Injury. Archives of Physical and Medical Rehabilitation, 2009, vol. 90, no. 5, p. 876-885. doi: 10.1016/j.apmr.2009.01.009

2. Healy D. The creation of psychopharmacology. Harvard: Harvard University Press, 2009, 469 p. ISBN 978-0674006195

3. Perlmuter L.C., Sarda G., Casavant V., Mosnaim A.D. A review of the etiology, associated comorbidities, and treatment of orthostatic hypotension. American Journal of Therapeutics, 2013, vol. 20, no.3, pp. 279-291. doi: 10.1097/ MJT.0b013e31828bfb7f

4. Jones P.K., Shaw B.H., Raj S.R. Orthostatic hypotension: managing a difficult problem. Expert Review of Cardiovascular Therapy, 2015, vol. 13, no. 11, pp. 1263-1276. doi: 10.1586/14779072.2015.1095090

5. Arbogast S.D., Alshekhlee A., Hussain Z., McNeeley K., Chelimsky T.C. Hypotension unawareness in profound orthostatic hypotension. American Journal of Medicine, 2009, vol. 122, no. 6, pp. 574-580. doi: 10.1016/j.amjmed.2008.10.040

6. Robertson D., Kincaid D.W., Haile V., Robertson R.M. The head and neck discomfort of autonomic failure: an unrecognized aetiology of headache. Clinical Autonomic Research, 1994, vol. 4, no. 3, pp. 99-103. doi: 10.1007/BF01845772

7. Khurana R.K. Coat-hanger ache in orthostatic hypotension. Cephalalgia, 2012, vol. 32, no. 10, pp. 731-737. doi: 10.1177/0333102412449932

8. Sullivan S.D., Hanauer J., Rowe P.C., Barron D.F., Darbari A., Oliva-Hemker M. Gastrointestinal symptoms associated with orthostatic intolerance. Journal of Pediatric Gastroenterology and Nutrition, 2005, vol. 40, no. 4, pp. 425-428. doi: 10.1097/01.MPG.0000157914.40088.31

9. Deb A., Morgenshtern K., Culbertson C.J., Wang L.B., Hohler A.D. A survey-based analysis of symptoms in patients with postural orthostatic tachycardia syndrome. Baylor University Medical Center Proceedings, 2015, vol. 28, no. 2, pp. 157-159. doi: 10.1080/08998280.2015.11929217

10. Rye D.B. Sleepiness and Unintended Sleep in Parkinson's Disease. Current Treatment Options in Neurology, 2003, vol. 5, no. 3, pp. 231-239. doi: 10.1007/ s11940-003-0014-z

11. Robinson M.J. Are newer antidepressants really «better tolerated»? The Canadian Journal of Psychiatry, 2001, vol. 46, no.3, pp. 286-287. doi: 10.1177/070674370104600314

12. Frewen J., Savva G.M., Boyle G., Finucane C., Kenny R.A. Cognitive performance in orthostatic hypotension: findings from a nationally representative 
sample. Journal of the American Geriatrics Society, 2014, vol. 62, no.1, pp. 117-122. doi: $10.1111 /$ jgs. 12592

13. Reggiani P., Magrini F., Mondadori C., Branzi G., Zanchetti A. Marked blood pressure fluctuations during narcoleptic attacks alternating with abnormal wakefulness: effects of treatment with clonidine. European Heart Journal, 1989, vol. 10, no. 1, pp. 2-7. doi: 10.1093/oxfordjournals.eurheartj.a059376

14. Casavant V., Chae C., Sherwani A., Perlmutter L.C. Subclinical orthostatic pulse pressure confirms mothers' ratings of ADHD in preschoolers. Psychophysiology, 2012, vol. 49, no. 5, pp. 708-712. doi: 10.1111/j.1469-8986.2012.01351.x

15. Kotagal V., Lineback C., Bohnen N.I., Albin R.L. Orthostatic hypotension predicts motor decline in early Parkinson disease. Parkinsonism and Related Disorders, 2016, vol. 32, pp. 127-129. doi: 10.1016/j.parkreldis.2016.09.011

16. Kojima T., Tada K. Neuroleptics and antidepressants. No To Shinkei, 1992, vol. 44, no. 12, pp. 1077-1082.

17. Schwartz J.T., Brotman A.W. A clinical guide to antipsychotic drugs. Drugs, 1992, vol. 44, no. 6, pp. 981-992. doi: 10.2165/00003495-199244060-00007

18. Cavanaugh R.M. Jr. Evaluating adolescents with fatigue: ever get tired of it? $\mathrm{Pe}$ diatrics in Review, 2002, vol. 23, no. 10, pp. 337-348. doi: 10.1542/pir.23-10-337

19. Czajkowska J., Ozhog S., Smith E., Perlmutter L.C. Cognition and hopelessness in association with subsyndromal orthostatic hypotension. The Journals of Gerontology: Series A, 2010, vol. 65, no. 8, pp. 873-879. doi: 10.1093/gerona/glq068

20. Regan C.O., Kearney P.M., Cronin H., Savva G.M., Lawlor B.A., Kenny R. Oscillometric measure of blood pressure detects association between orthostatic hypotension and depression in population based study of older adults. $B M C$ Psychiatry, 2013, vol. 13, p. 266. doi: 10.1186/1471-244X-13-266

21. Modugno N., Lena F., Di Biasio F., Cerrone G., Ruggieri S., Fornai F. A clinical overview of non-motor symptoms in Parkinson's Disease. Archives Italiennes de Biologie, 2013, vol. 151, no. 4, pp. 148-168.

22. Ricci F., De Caterina R., Fedorowski A. Orthostatic Hypotension: Epidemiology, Prognosis, and Treatment. Journal of American College of Cardiology, 2015, vol. 66, no. 7, pp. 848-860. doi: 10.1016/j.jacc.2015.06.1084

23. Gupta V., Lipsitz L.A. Orthostatic hypotension in the elderly: diagnosis and treatment. American Journal of Medicine, 2007, vol. 120, no. 10, pp. 841-847. doi: 10.1016/j.amjmed.2007.02.023

24. Chou R.H., Liu C.J., Chao T.F., Chen S.J., Tuan T.C., Chen T.J., Chen S.A. Association between orthostatic hypotension, mortality, and cardiovascular disease in Asians. International Journal of Cardiology, 2015, vol. 195, pp. 40-44. doi: 10.1016/j.ijcard.2015.05.060 
25. Edgell H., Robertson A.D., Hughson R.L. Hemodynamics and brain blood flow during posture change in younger women and postmenopausal women compared with age-matched men. Journal of Applied Physiology, 2012, vol. 112, no. 9, pp. 1482-1493. doi: 10.1152/japplphysiol.01204.2011

26. Van Dijk N., Wieling W. Fainting, emancipation and the 'weak and sensitive' sex. The Journal of Physiology, 2009, vol. 587, no. 13, pp. 3063-3064. doi: 10.1113/jphysiol.2009.174672

27. Canada S.A., Hofkamp M., Gall E.P., Perlmuter L.C. Estrogen replacement therapy, subsyndromal depression, and orthostatic blood pressure regulation. Behavioral Medicine, 2003, vol. 29, no. 3, pp. 101-106. doi: 10.1080/08964280309596062

28. Lide B., Haeri S. A Case Report and Review of Postural Orthostatic Tachycardia Syndrome in Pregnancy. American Journal of Perinatology Reports, 2015, vol. 5, no. 1, pp. e33-e36. doi: 10.1055/s-0034-1544106

29. Barnes T.R., Katona C.L. Susceptibility to drug-induced hypotension in post-partum psychosis. International Clinical Psychopharmacology, 1986, vol. 1, no. 1, pp. 74-76. doi: 10.1097/00004850-198601000-00009

30. Strogatz D.S., Keenan N.L., Barnett E.M., Wagner E.H. Correlates of postural hypotension in a community sample of elderly blacks and whites. Journal of the American Geriatrics Society, 1991, vol. 39, no. 6, pp. 562-566. doi: 10.1111/ j.1532-5415.1991.tb03593.x

31. Shvartz E., Wyndham C.H., Strydom N.B. Orthostatic responses in Caucasians and Bantu. Aviation, Space and Environmental Medicine, 1975, vol. 46, no. 11, pp. 1343-1348.

32. Clark R., Tyroler H.A., Heiss G. Orthostatic blood pressure responses as a function of ethnicity and socioeconomic status: the ARIC study. Annals of the New York Academy of Sciences, 1999, vol.896, pp. 316-317. doi: 10.1111/j.17496632.1999.tb08127.x

33. Kuruvilla A., Jacob K.S. Poverty, social stress and mental health. The Indian Journal of Medical Research, 2007, vol. 126, no. 4, pp. 273-278.

34. Ludwig D.A., Convertino V.A. Predicting orthostatic intolerance: physics or physiology? Aviation, Space and Environmental Medicine, 1994, vol. 65, no. 5, pp. 404-411.

35. Lee J.F., Harrison M.L., Christmas K.M., Kim K., Hurr C., Brothers R.M. Elevated resting heart rate and reduced orthostatic tolerance in obese humans. Clinical Autonomic Research, 2014, vol. 24, no. 1, pp. 39-46. doi: 10.1007/s10286-013-0222-x

36. Maser R.E., Lenhard M.J. An overview of the effect of weight loss on cardiovascular autonomic function. Current Diabetes Reviews, 2007, vol. 3, no. 3, pp. 204-211. doi: 10.2174/157339907781368931 
37. Narkiewicz K., Cooley R.L., Somers V.K. Alcohol potentiates orthostatic hypotension: implications for alcohol-related syncope. Circulation: Journal of the American Heart Association, 2000, vol. 101, no. 4, pp. 398-402. doi: 10.1161/01.cir.101.4.398

38. Carter J.R., Stream S.F., Durocher J.J., Larson R.A. Influence of acute alcohol ingestion on sympathetic neural responses to orthostatic stress in humans. American Journal of Physiology-Endocrinology and Metabolism, 2011, vol. 300, no. 5, pp. E771-E778. doi: 10.1152/ajpendo.00674.2010

39. Gaxatte C., Faraj E., Lathuillerie O., Salleron J., Deramecourt V., Pardessus V., Destailleur M.H., Boulanger E., Puisieux F. Alcohol and psychotropic drugs: risk factors for orthostatic hypotension in elderly fallers. Journal of Human Hypertension, 2017, vol. 31, no. 4, pp. 299-304. doi: 10.1038/jhh.2013.82

40. Merritt J.C., Cook C.E., Davis K.H. Orthostatic hypotension after delta 9-tetrahydrocannabinol marihuana inhalation. Ophthalmic Research, 1982, vol. 14, no. 2, pp. 124-128. doi: 10.1159/000265183

41. Benowitz N.L., Jones R.T. Cardiovascular and metabolic considerations in prolonged cannabinoid administration in man. The Journal of Clinical Pharmacology, 1981, vol. 21, no. S1, pp. 214S-223S. doi: 10.1002/j.1552-4604.1981. tb02598.x

42. LaWall J.S. Treatment of psychotropic-caused orthostatic hypotension. Psychosomatics, 1980, vol. 21, no. 8, pp. 693-694. doi: 10.1016/S00333182(80)73636-8

43. Knight J., Nigam Y., Jones A. Effects of bedrest 1: cardiovascular, respiratory and haematological systems. Nursing Times, 2009, vol. 105, no. 21, pp. 16-20.

44. Bykov Yu.V., Bekker R.A., Reznikov M.K. Depressii i rezistentnost'. [Depressions and treatment resistance]. Moscow: RIOR Publ., 2013. 374 p. ISBN 9785-369-01096-9

45. Llach F., Weidmann P., Reinhart R., Maxwell M.H., Coburn J.W., Massry S.G. Effect of acute and long-standing hypocalcemia on blood pressure and plasma renin activity in man. The Journal of Clinical Endocrinology and Metabolism, 1974, vol. 38, no.5, pp. 841-847. doi: 10.1210/jcem-38-5-841

46. Antiel R.M., Caudill J.S., Burkhardt B.E., Brands C.K, Fischer P.R. Iron insufficiency and hypovitaminosis $\mathrm{D}$ in adolescents with chronic fatigue and orthostatic intolerance. Southern Medical Journal, 2011, vol. 104, no. 8, pp. 609-611. doi: 10.1097/SMJ.0b013e3182246809

47. Lukkarinen H., Peltola V. Influenza A induced acute autonomic neuropathy in an adolescent. Pediatric Neurology, 2010, vol. 43, no. 6, pp. 425-426. doi: 10.1016/j.pediatrneurol.2010.06.011 
48. Summers Q., Harris A. Autonomic neuropathy after rubella infection. Medical Journal of Australia, 1987, vol. 147, no. 7, pp. 353-355. 10.5694/j.13265377.1987.tb133521.x

49. Clegg A., Daverede L., Wong W., Loney E., Young J. Recurrent syncope and chronic ear pain. BMJ Case Reports, 2010, pii: bcr0620103109. doi: 10.1136/ bcr.06.2010.3109

50. Itoh Y., Oishi T., Ohnishi A. Acute cerebellar ataxia with sympathotonic orthostatic hypotension following Epstein-Barr virus infection--a case report. Rinsho Shinkeigaku, 1993, vol. 33, no. 5, pp. 503-506.

51. Prange H. Possible involvement of the autonomic nervous system in herpes zoster. Der Internist, 1996, vol. 37, no. 11, pp. 1168-1169.

52. Tamura N., Shimazu K., Yamamoto T., Itokawa K., Hamaguchi K. A case of sympathotonic orthostatic hypotension following herpes simplex encephalitis. Rinsho Shinkeigaku, 1996, vol. 36, no. 10, pp. 1161-1165.

53. Kleiter I., Steinbrecher A., Flügel D., Bogdahn U., Schulte-Mattler W. Autonomic involvement in tick-borne encephalitis (TBE): report of five cases. European Journal of Medical Research, 2006, vol. 11, no. 6, pp. 261-265.

54. Johnson K., Sargent L.A., Galizio C., Ubogu E.E. Interferon-alpha-2b/ribavirin-induced vestibulocochlear toxicity with dysautonomia in a chronic hepatitis C patient. European Journal of Gastroenterology and Hepatology, 2008, vol. 20, no. 11, pp. 1110-1114. doi: 10.1097/MEG.0b013e3282f8e583

55. Nakao K., Namekawa M., Kondo S., Ono S., Nakano I. Subacute autonomic and sensory neuropathy closely related to cytomegalovirus infection preceded by frequent syncopal attacks. Rinsho Shinkeigaku, 2016, vol. 56, no. 8, pp. 555559. doi: 10.5692/clinicalneurol.cn-000863

56. DeYoung P., Martyn J., Wass H., Harth L., Crichton E., Reynolds C. Toxic shock syndrome associated with a contraceptive diaphragm. Canadian Medical Association Journal, 1982, vol. 127, no. 7, pp. 611-612.

57. Cohen J.A., Miller L., Polish L. Orthostatic hypotension in human immunodeficiency virus infection may be the result of generalized autonomic nervous system dysfunction. Journal of Acquired Immune Deficiency Syndromes, 1991, vol. 4, no. 1, pp. 31-33.

58. Grange C., Augey L., Durieu I., Vital Durand D., Levrat R. Orthostatic hypotension revealing HIV infection. Presse Medicale, 1993, vol. 22, no. 34, p. 1748.

59. Dore M.X., de La Blanchardière A., Lesprit P., David F., Beressi J.P., Fiet J., Sicard D., Decazes J.M. Peripheral adrenal insufficiency in AIDS. La Revue de Medecine Interne, 1998, vol. 19, no. 1, pp. 23-28. doi: 10.1016/S02488663(97)83695-8 
60. Pathak A., Lapeyre-Mestre M., Montastruc J.L., Senard J.M. Heat-related morbidity in patients with orthostatic hypotension and primary autonomic failure. Movement Disorders, 2005, vol. 20, no. 9, pp. 1213-1219. doi: 10.1002/mds.20571

61. McCarthy P., Snyder J.C. Orthostatic hypotension: a potential side effect of psychiatric medications. Journal of Psychosocial Nursing and Mental Health Services, 1992, vol. 30, no. 8, pp. 3-5. doi: 10.3928/0279-3695-19920801-05

62. Stahl S.M. Stahl's Essential Psychopharmacology. Neuroscientific Basis and Practical Application. Cambridge:Cambridge University Press, 2013, 628 p. ISBN 978-1107025981

63. Choi W.J., Lee K., Kim Y.K, Song K.J., Jeong S.M., Hwang G.S. Vagolytic atropine attenuates cerebral vasodilation response during acute orthostatic hypotension. Korean Journal of Anesthesiology, 2015, vol. 68, no. 6, pp. 594-602. doi: $10.4097 / \mathrm{kjae} .2015 .68 .6 .594$

64. Jefferson J.W. Atypical manifestations of postural hypotension. Archives of General Psychiatry, 1972, vol. 27, no. 2, pp. 250-251. doi: 10.1001/archpsyc.1972.01750260092014

65. Bekker R.A., Bykov Yu.V. Akatiziya: klinicheskiy analiz patologii s rekomendatsiyami i obzorom literatury. [Akathisia: a clinical analysis of the pathology with recommendations and a literature review]. Available at URI: https://conmed.ru/partner_article/all/akatiziya-klinicheskiy-analiz-patologii-s-rekomendatsiyami-i-obzorom-literatury/. Availability checked: 10.09.2019.

66. Ducloux G., Manouvrier J., Wemeau J.L., Christiaens J.L., Barbry M., Sarkis E.H. Orthostatic hypotension due to prolactin-secreting pituitary adenoma. American Heart Journal, 1984, vol. 107, no. 1, pp. 187-188. doi: 10.1016/00028703(84)90164-9

67. Ibarra F., Crambert S., Eklöf A.C., Lundquist A., Hansell P., Holtbäck U. Prolactin, a natriuretic hormone, interacting with the renal dopamine system. Kidney International, 2005, vol. 68, no. 4, pp. 1700-1707. doi: 10.1111/j.15231755.2005.00586.x

68. Brakha S. Orthostatic hypertension, a constant symptom of endogenous depressive attacks due to cerebral noradrenergic hypofunction. Revue Neurologique, 1972, vol. 127, no. 2, pp. 323-325.

69. Mazo G.E., Neznanov N.G. Terapevticheski rezistentnye depressii. [Treatment resistant depression]. Saint Petersburg: Beresta Publ., 2012. 448 p. ISBN 9785-905225-48-2

70. Darowski A., Chambers S.A., Chambers D.J. Antidepressants and falls in the elderly. Drugs and Aging, 2009, vol. 26, no. 5, pp. 381-394. doi: 10.2165/00002512200926050-00002 
71. Stage K.B. Orthostatic side effects of clomipramine and moclobemide during treatment for depression. Nordic Journal of Psychiatry, 2005, vol. 59, no. 4, pp. 298-301. doi: 10.1080/08039480500213725

72. Feighner J.P. The role of venlafaxine in rational antidepressant therapy. The Journal of Clinical Psychiatry, 1994, vol. 55, no. Suppl. A, pp. 62-68.

73. Feighner J.P. Cardiovascular safety in depressed patients: focus on venlafaxine. The Journal of Clinical Psychiatry, 1995, vol. 56, no. 12, pp. 574-579.

74. Chikkaramanjegowda V., de Leon J. Venlafaxine-induced orthostatic hypotension in a geriatric patient. Case Reports in Psychiatry, 2013, article id: 761567. doi: $10.1155 / 2013 / 761567$

75. Duggal H.S., Jagadheesan K., Nizamie HS. Venlafaxine-induced orthostatic hypotension. Indian Journal of Psychiatry, 2001, vol. 43, no. 4, pp. 371-373.

76. Gorman J.M. The use of newer antidepressants for panic disorder. The Journal of Clinical Psychiatry, 1997, vol. 58, no. Suppl 14, pp. 54-58.

77. Bulut S., Berilgen M.S., Baran A., Tekatas A., Atmaca M., Mungen B. Venlafaxine versus amitriptyline in the prophylactic treatment of migraine: randomized, double-blind, crossover study. Clinical Neurology and Neurosurgery, 2004, vol. 107, no. 1, pp. 44-48. doi: 10.1016/j.clineuro.2004.03.004

78. Haanpää M.L., Gourlay G.K., Kent J.L., Miaskowski C., Raja S.N., Schmader K.E., Wells C.D. Treatment considerations for patients with neuropathic pain and other medical comorbidities. Mayo Clinic Proceedings, 2010, vol. 85, no. Suppl 3, pp. S15-S25. doi: 10.4065/mcp.2009.0645

79. Johnson E.M., Whyte E., Mulsant B.H., Pollock B.G., Weber E., Begley A.E., Reynolds C.F. Cardiovascular changes associated with venlafaxine in the treatment of late-life depression. The American Journal of Geriatric Psychiatry, 2006, vol. 14, no. 9, pp. 796-802. doi: 10.1097/01.JGP.0000204328.50105.b3

80. Wernicke J., Lledó A., Raskin J., Kajdasz D.K., Wang F. An evaluation of the cardiovascular safety profile of duloxetine: findings from 42 placebo-controlled studies. Drug Safety, 2007, vol. 30, no. 5, pp. 437-455. doi: 10.2165/00002018200730050-00007

81. Raskin J., Wiltse C.G., Dinkel J.J., Walker D.J., Desaiah D., Katona C. Safety and tolerability of duloxetine at $60 \mathrm{mg}$ once daily in elderly patients with major depressive disorder. Journal of Clinical Psychopharmacology, 2008, vol. 28, no. 1, pp. 32-38. doi: 10.1097/jcp.0b013e318160738e

82. Leinonen E., Lepola U., Koponen H., Mehtonen O.P., Rimon R. Long-term efficacy and safety of milnacipran compared to clomipramine in patients with major depression. Acta Psychiatrica Scandinavica, 1997, vol. 96, no. 6, pp. 497-504. doi: 10.1111/j.1600-0447.1997.tb09953.x 
83. Mago R., Mahajan R., Thase M.E. Levomilnacipran: a newly approved drug for treatment of major depressive disorder. Expert Review of Clinical Pharmacology, 2014, vol. 7, no. 2, pp. 137-145. doi: 10.1586/17512433.2014.889563

84. Bruno A., Morabito P., Spina E., Muscatello M.R. The Role of Levomilnacipran in the Management of Major Depressive Disorder: A Comprehensive Review. Current Neuropharmacology, 2016, vol. 14, no. 2, pp. 191-199. doi: 10.2174/1 570159X14666151117122458

85. Rasmussen K.G., Leise A.D., Stevens S.R. Orthostatic hemodynamic changes after electroconvulsive therapy treatments. The Journal of ECT, 2008, vol. 24, no. 2, pp. 134-136. doi: 10.1097/YCT.0b013e318156dffb

86. Bykov Yu.V. Elektrosudorozhnaya terapiya v praktike anesteziologa. [Electroconvulsive therapy in an anesthesiologist's practice]. Moscow: RIOR Publ., 2013. 222 p. ISBN 978-5-369-01140-9

87. Bykov Yu.V., Bekker R.A. Minimizatsiya kognitivnykh narusheniy pri elektrosudorozhnoy terapii: realii i perspektivy (I chast': teoreticheskaya). [Minimizing ECT cognitive side effects: current clinical reality and future perspectives (Part I: theoretical)]. V mire nauchnykh otkrytiy [Siberian Journal of Life Sciences and Agriculture], 2016, vol. 10, no. 82, pp. 54-92. doi: 10.12731/wsd2016-10-54-92

88. Bykov Yu.V., Bekker R.A. Minimizatsiya kognitivnykh narusheniy pri elektrosudorozhnoy terapii: realii i perspektivy (obzor literatury s kommentariyami i rekomendatsiyami) (II chast': prakticheskaya). [Minimizing ECT cognitive side effects: current clinical reality and future perspectives (Part II: practical)]. $V$ mire nauchnykh otkrytiy [Siberian Journal of Life Sciences and Agriculture], 2016, vol. 12, no. 84, pp. 200-272. doi: 10.12731/wsd-2016-12-200-272

89. Bykov Yu.V., Nelson A.I. Atropinokomatoznaya terapiya: vzglyad na problemu (Obzor literatury) [Atropine coma therapy: a view on the problem with a literature review]. Available at URI: https://psychoreanimatology.org/modules/ articles/article.php?id=61 Availability checked at: 10.09.2019

90. Kalser M.H., Frye C.W., Gordon A.S. Postural hypotension induced by atropine sulfate. Circulation, 1954, vol. 10, no. 3, pp. 413-422. doi: 10.1161/01. cir.10.3.413

91. Thulesius O. Therapy of arterial hypotension. Die Medizinische Welt, 1975, vol. 26 , no. 13 , pp. $588-591$.

92. Weise F., Baltrusch K., Heydenreich F. Effect of low-dose atropine on heart rate fluctuations during orthostatic load: a spectral analysis. Journal of the Autonomic Nervous System, 1989, vol. 26, no.3, pp. 223-230. 10.1016/01651838(89)90171-9 
93. Smith M., Ray C.T. Cardiac arrhythmias, increased intracranial pressure, and the autonomic nervous system. Chest, 1972, vol. 61, no. 2, pp. 125-133. doi: 10.1378/chest.61.2.125

94. Saito Y., Ishikawa J., Harada K. Postprandial and Orthostatic Hypotension Treated by Sitagliptin in a Patient with Dementia with Lewy Bodies. The American Journal of Case Reports, 2016, vol. 17, pp. 887-893. doi: 10.12659/ AJCR.900620

95. Nelson A.I. Kratkoe posobie dlya vrachey po primeneniyu metoda forsirovannoy insulinokomatoznoy terapii (FIKT) [A short guideline for doctors practicing fortified insulin coma therapy]. Available at URI: https://psychoreanimatology. org/modules/articles/article.php?id=27 Availability checked at: 10.09.2019

96. Brown R.T., Polinsky R.J., Lee G.K., Deeter J.A. Insulin-induced hypotension and neurogenic orthostatic hypotension. Neurology, 1986, vol. 36, no. 10, pp. 1402-1406. doi: 10.1212/wnl.36.10.1402

97. Ishikawa Y., Shimatsu A., Imura H., Tatsuoka Y., Fujitake J. Effects of insulin-induced hypoglycemia on catecholamine secretion and blood pressure in neurological disorders affecting autonomic nervous system. Rinsho Shinkeiga$k u$, 1992, vol. 32, no. 3, pp. 281-286.

98. Robillard R., Lanfranchi P.A., Prince F., Filipini D., Carrier J. Sleep deprivation increases blood pressure in healthy normotensive elderly and attenuates the blood pressure response to orthostatic challenge. Sleep, 2011, vol. 34, no. 3, pp. 335-339. doi: 10.1093/sleep/34.3.335

99. Grenon S.M., Hurwitz S., Sheynberg N., Xiao X., Judson B., Ramsdell C.D., Kim C., Cohen R.J., Williams G.H. Sleep restriction does not affect orthostatic tolerance in the simulated microgravity environment. Journal of Applied Physiology, 2004, vol. 97, no. 5, pp. 1660-1666. doi: 10.1152/japplphysiol.00328.2004

100. Calvin A.D., Caples S.M. Getting to the heart of sleep deprivation. Sleep, 2011, vol. 34, no. 3, pp. 251-252. doi: 10.1093/sleep/34.3.251

101. Lin Y.C., Shiraki K., Takeuchi H., Mohri M. Cardiovascular deconditioning occurs during a 7-day saturation dive at 31 ATA. Aviation, Space, and Environmental Medicine, 1995, vol. 66, no. 7, pp. 656-660.

102. Claybaugh J.R., Lin Y.C., Schafstall H.G., Bennett P.B. Cardiovascular and endocrine responses to 90 degree tilt during a 35-day saturation dive to 46 and 37 ATA. Aviation, Space, and Environmental Medicine, 2007, vol. 78, no. 11, pp. 1042-1049.

103. Bekker R.A., Bykov Yu.V. Sul'fozin - produkt psikhiatricheskoy shkoly SSSR: terapevticheskiy agent ili sredstvo karatel'noy psikhiatrii? [Sulfozine as a 
product of Soviet psychiatry: Was it solely a «repressive and discipline-pushing» measure, or really a useful therapeutic agent?]. V mire nauchnykh otkrytiy [Siberian Journal of Life Sciences and Agriculture], 2017, vol. 2, no. 9, pp. 214-242. doi: 10.12731/wsd-2017-2-214-242

104. Bykov Yu.V., Bekker R.A. Pirogenal v psikhiatrii, nevrologii i narkologii: istoriya, mekhanizmy lechebnogo vozdeystviya i rezul'taty. [Pyrogenal in psychiatry, addiction medicine and neurology: history of its use, hypotheses on its mechanisms of action and therapeutic results]. V mire nauchnykh otkrytiy [Siberian Journal of Life Sciences and Agriculture], 2017, vol. 4-2, no. 9, pp. 101-136. doi: 10.12731/wsd-2017-4-2-101-136

105. Gambhir S., Sandersfeld N., D’Mello D. A Case of Severe, Refractory Antipsychotic-Induced Orthostatic Hypotension. Medical Student Research Journal, 2014. doi: $10.3402 / \mathrm{msrj} . \mathrm{v} 3 \mathrm{i} 0.201337$

\section{ДАННЫЕ ОБ АВТОРАХ}

Беккер Роман Александрович, программист, инженер-математик, магистр в области компьютерных наук, исследователь лаборатории автономных роботов, факультет электроники и компьютерных наук

Университет им. Давида Бен-Гуриона в Негеве а/я 653, Беер-Шева, 8410501, Израиль rbekker1@gmail.com

Быков Юрий Витальевич, врач анестезиолог-реаниматолог, врач психиатр-нарколог, кандидат медицинских наук, ассистент кафедры анестезиологии, реаниматологии и скорой медицинской помощи, педиатрический факультет

Ставропольский Государственный Медицинский Университет ул. Мира, 310, г. Ставрополь, Ставропольский край, Российская Федерачия yubykov@gmail.com

DATA ABOUT THE AUTHORS

Bekker Roman Aleksandrovich, Programmer, Computer Engineer, Magister of Computer Science, Research Officer at the Laboratory of Autonomous Security Systems (Robotics), Faculty of Electrical and Computer Engineering Ben-Gurion University of the Negev 
bulv. Ben-Gurion, Beer-Sheva, 8410501, Israel

rbekker1@gmail.com

ORCID: 0000-0002-0773-3405

ResearcherID: J-7724-2016

Bykov Yuriy Vitalevich, $\mathrm{PhD}$, anesthesiologist, psychiatrist, addiction medicine specialist, Candidate of Medical Sciences, Teaching Assistant at the Department of Anesthesiology, Reanimatology and Emergency Care, Department of Pediatrics

Stavropol State Medical University

310, Mira Str., Stavropol, Russian Federation

yubykov@gmail.com

ORCID: 0000-0003-4705-3823

ResearcherID: K-1888-2016 